Dear Prof. Lisanti, Editor-in-Chief,

thank you very much for the opportunity to submit a second revised version of the paper 'Autophagic degradation contributes to muscle wasting in cancer cachexia'. The paper has been modified according to the reviewer's suggestions, including the experiments on differentiated myotubes (last point raised by the reviewer), despite these were not required in the first revision. The data obtained by treating $\mathrm{C} 2 \mathrm{C} 12$ myotubes with low TNFa concentrations ( $5 \mathrm{ng} / \mathrm{ml})$, as well as those obtained by injecting the cytokine in the skeletal muscle of intact animals, have now been provided. Just a comment, in this regard: we are asked to expose $\mathrm{C} 2 \mathrm{C} 12$ cultures to 'physiological' concentrations of TNFa, and, on the other side, to verify that this cytokine induces muscle autophagy in vivo. However, all the possible ways to test TNFa effects in vivo, including those suggested by the reviewer, require (Moresi V. et al., PLoS ONE 4:e5570, 2009), or result in (Oliff A. et al., Cell, 50:555-563,1987; Coletti D. et al., Genesis, 43:120-128, 2005) high, markedly supraphysiological concentrations of the cytokine, that will very likely affect the whole organism and not just the treated muscle. As an example, the study by Coletti and coworkers demonstrates that TNFa gene transfer into the skeletal muscle induces systemic cachexia. In conclusion, with the due respect, we wonder about the physiological significance of the results obtained from such a study, and this was precisely the reason that lead us to discard the execution of the experiment during the first revision.

We really hope that in the present version the paper would become suitable for publication in The American Journal of Pathology.

Best regards.

Paola Costelli

\title{
Point-by-point reply
}

- a more accurate attempt to define the novelty of the present study in comparison with the data already available in the literature has been performed. Previous studies reporting data pertinent to the activation of autophagy in the model systems used in the present paper have been cited in the Introduction, taking care to underline the differences in terms of both approaches and results (page 4, lines 1025) and not only in the Discussion as in the previous revised version;

- the experiments on $\mathrm{C} 2 \mathrm{C} 12$ cultures have been repeated by using TNFa $5 \mathrm{ng} / \mathrm{ml}$, in the presence or in the absence of bafilomycin $A$ in order to assess also the 
'autophagic flux'. The data are reported in Figure S4B and in the Result section (page 12, line 28 - page 13, line 5). Such experiments have been performed on fully differentiated myotubes ( 6 days after switch to differentiation medium), as requested by the reviewer, although this point was not raised in the first revision;

- an in vivo experiment has been performed to investigate if TNFa directly induces autophagy in the skeletal muscle. According to the reviewer's suggestion, we injected the cytokine in the gastrocnemius muscle of healthy mice. The results are shown in Figure S5 and discussed in the text (page 13, lines 14-19). TNFa concentration ( $40 \mu \mathrm{g} / \mathrm{kg}$ body weight) has been selected according to the data available in the literature (Langen et al., FASEB J, 18:227-237, 2004). Untreated mice have been used as controls, in order to avoid biases due to the probable systemic effects of intramuscular TNFa injection. 


\section{AUTOPHAGIC DEGRADATION CONTRIBUTES TO MUSCLE WASTING IN CANCER CACHEXIA}

Fabio Penna ${ }^{1^{*}}$, Domiziana Costamagna ${ }^{1^{*}}$, Fabrizio Pin $^{1^{*}}$, Andrea Camperi $^{\mathbf{1}^{*}}$, Alessandro Fanzani ${ }^{2^{*}}$, Elena M. Chiarpotto ${ }^{3}$, Gabriella Cavallini ${ }^{4}$, Gabriella Bonelli ${ }^{1}$, Francesco M. Baccino ${ }^{1}$, Paola Costelli $^{1^{*}}$

\footnotetext{
${ }^{1}$ Department of Experimental Medicine and Oncology, University of Torino, Italy ${ }^{2}$ Department of Biomedical Sciences and Biotechnology, University of Brescia, Italy ${ }^{3}$ Department of Clinical and Biological Sciences, University of Torino, Italy ${ }^{4}$ Interdepartmental Research Center on Biology and Pathology of Aging, University of Pisa, Italy *Interuniversitary Institute of Myology (IIM), Italy
}

Running title: autophagy in cachexia

Corresponding author: Paola Costelli,

Department of Experimental Medicine and Oncology,

Corso Raffaello, 30, 10125 Torino, Italy, phone: +39-0116707062, fax: +39-0116707753, e-mail: paola.costelli@unito.it

Key words: autophagy, muscle wasting, cancer cachexia, dexamethasone, aging

Work supported by Associazione Italiana per la Ricerca sul Cancro (AIRC - F.P.: MFAG6211; P.C.: IG9153), Milano, Ministero per l'Università e la Ricerca, Roma (PRIN projects), University of Torino (ex-60\% funds), Regione Piemonte, Compagnia di San Paolo, Torino, Italy. 


\section{$1 \quad$ ABSTRACT}

Muscle protein wasting in cancer cachexia is a critical problem. The underlying mechanisms are still unclear, although the ubiquitin-proteasome system has been involved in the degradation

4 of bulk myofibrillar proteins. The present work has been aimed to investigate if also autophagic degradation plays a role in the onset of muscle depletion in cancer-bearing animals as well as in

6 glucocorticoid-induced atrophy and sarcopenia of aging. The results show that autophagy is 7 induced in muscle in three different models of cancer cachexia as well as in glucocorticoid-treated 8 mice. By contrast, autophagic degradation in the muscle of sarcopenic animals is impaired, but can 9 be reactivated by calorie restriction. These results further demonstrate that different mechanisms 10 are involved in pathological muscle wasting, and that autophagy, either excessive or defective, contributes to the complicated network that leads to muscle atrophy. In this regard, particularly 12 intriguing is the observation that in both cancer hosts and TNF $\alpha$-treated C2C12 myotubes insulin can only partially blunt autophagy induction. This would suggest that autophagy is triggered through mechanisms that cannot be circumvented by using classical up-stream modulators, prompting to identify more effective approaches to target this proteolytic system. 


\section{INTRODUCTION}

Cancer cachexia is a multifactorial syndrome characterized by anorexia, weight loss and muscle wasting that significantly impairs patients' quality of life and survival, also reducing their tolerance to anti-neoplastic treatments. Despite the relevance of cachexia to patient outcome, however, effective cachexia treatments are still lacking, and only recently tumor-induced wasting is becoming to be considered as a prognostic tool ${ }^{1}$.

The mechanisms underlying muscle wasting in cancer cachexia are still unclear, although experimental and clinical studies have shown that hyperactivation of the ubiquitin-proteasomedependent proteolytic system plays a critical role ${ }^{2,3}$. In this regard, however, in the last few years the involvement of autophagic-lysosomal proteolysis has also been proposed. The lysosomal degradative system contributes to different cellular processes, such as degradation of cytoplasmic proteins and organelles, limited cleavage or extensive degradation of various substrates, trafficking and recycling of molecules among internal organelles to and from the exterior of the cell, post-translational maturation of secretory products and storage of undigested material ${ }^{4}$. Autophagy is the major process for degradation of cellular constituents, its rate being enhanced under stress conditions leading to organelle damage or under marked nutrients restriction (starvation), in order to recycle biomolecules for the synthesis of essential constituents ${ }^{5}$. In such conditions, autophagy has been shown to operate bulk proteolysis in most visceral tissues, such as the liver ${ }^{6}$, while its role in the skeletal muscle has been emerging only during the last years. In this regard, few years ago a study reported for the first time that starvation-induced autophagy also occurs in the skeletal muscle ${ }^{7}$, and quite recently autophagy has been shown to contribute to starvation-induced muscle atrophy, with a mechanism involving TNF $\alpha$ receptor-associated factor (TRAF)6/Fn14 signaling ${ }^{8}$. An altered lysosomal function has also been reported in several myopathies ${ }^{9}$ and, more recently, autophagy-related genes (ATGs) have been shown to be induced in muscle by denervation or fasting, through a FoxO3-dependent mechanism ${ }^{10}$. In this regard, FoxO3 has been proposed to regulate both autophagy and proteasome-dependent proteolysis ${ }^{10}$. However, a sort of hierarchy appears to exist between these two processes, since a parallel study shows that autophagic degradation induced by starvation or FoxO3 overexpression is sufficient to determine muscle depletion even if the ubiquitin-proteasome degradation is blocked using pharmacological or genetic approaches ${ }^{11}$. 
As for cancer cachexia, results obtained on muscles isolated from cachectic animals led to rule out a substantial role for lysosomes in the overall protein degradation ${ }^{12}$. On the other hand, an elevation of total lysosomal protease activity has been observed in the skeletal muscle and liver of tumor-bearing rats ${ }^{13}$, and muscle depletion could be prevented by treatment of tumor hosts with leupeptin, an inhibitor of cysteine proteases such as cathepsins $B, H$, and $L{ }^{14}$. Finally, increased levels of cathepsin L mRNA have been reported in the skeletal muscle of septic or tumor-bearing rats, while cathepsin B gene expression has been shown to be enhanced in muscle biopsies obtained from lung cancer patients ${ }^{15,16}$.

The present work has been aimed to investigate the relevance of autophagy to the pathogenesis of skeletal muscle wasting in cancer cachexia. In this regard, only recently few and scanty observations suggested that autophagy can be activated in the muscle of animals bearing the Lewis lung carcinoma or the colon 26 tumor $^{8,17-19}$. However, a comprehensive analysis of the activation of the autophagic-lysosomal proteolytic pathway, including the evaluation of autophagic flux, in cancer hosts is still lacking. The present study fills this gap. Not only, cancerinduced muscle wasting has been compared, in terms of activation of autophagy, with that occurring in other experimental conditions such as glucocorticoid-induced atrophy and aging. On this line, previous data reported that autophagy significantly contributes to muscle wasting in different experimental conditions, such as denervation, starvation and sepsis ${ }^{10,20}$. However, while some of the mechanisms underlying glucocorticoid-induced atrophy have already been described 21-23, only two reports have provided little evidence, also indirect, about the involvement of autophagy ${ }^{24,25}$. The present study, extensively investigating the effects of glucocorticoid administration on the activation of muscle autophagy, clarifies this point. As for aging, only a couple of reports ${ }^{26,27}$ analyzed the modulations of muscle autophagy. The present study extends such findings providing a panel of autophagy markers in the aged muscle at protein levels, and comparing their changes with those occurring in aged animals exposed to $40 \%$ calorie restriction.

The results show that autophagic-lysosomal degradation is induced in three different models of cancer-associated muscle atrophy as well as in glucocorticoid-treated animals, suggesting this proteolytic system as a possible target of therapeutic strategies. 


\section{MATERIALS AND METHODS}

All materials were supplied by Sigma-Aldrich, unless differently specified.

\section{Animals and experimental design}

Experimental animals were cared for in compliance with the Italian Ministry of Health Guidelines ( $n^{\circ} 86609$ EEC, permit number 106/2007-B) and the Policy on Humane Care and Use of Laboratory Animals (NIH 1996). The experimental protocol was approved by the Bioethical Committee of the University of Torino. Male Wistar rats weighing about $150 \mathrm{~g}$, Balb-c and C57/BL6 mice weighing about $20 \mathrm{~g}$ were obtained from Charles River Laboratories, and maintained on a regular dark-light cycle (light from 08:00 to 20:00), with free access to food and water during the whole experimental period. Tumor-bearing rats $(n=8)$ received an intraperitoneal (i.p.) inoculum of Yoshida $\mathrm{AH}-130$ ascites hepatoma cells ( 108 cells/rat; provided many years ago by Prof. M. Del Monte, University of Milano, Italy, and maintained in our lab by weekly i.p. transplantation), while tumor-bearing mice $(n=8)$ were inoculated subcutaneously dorsally with 5x105 C26 carcinoma cells (kindly provided by Prof. M.P. Colombo, IRCCS National Cancer Institute, Milano, Italy) or intramuscularly with 5x105 Lewis Lung carcinoma cells (ATCC, USA). Both C26 and LLC cells were expanded in vitro $\left(50.000 \mathrm{~cm}^{2}\right.$, Dulbecco's Modified Eagle's Medium (DMEM) supplemented with $10 \% \mathrm{FBS}, 100 \mathrm{U} / \mathrm{ml}$ penicillin, $100 \mu \mathrm{g} / \mathrm{ml}$ streptomycin, $100 \mu \mathrm{g} / \mathrm{ml}$ sodium pyruvate, $2 \mathrm{mM} \mathrm{L-glutamine,} \mathrm{maintained} \mathrm{at} 37^{\circ} \mathrm{C}$ in a humidified atmosphere of $5 \% \mathrm{CO} 2$ in air), detached with trypsin, re-suspended in sterile saline and subsequently implanted in the animals at the concentrations indicated above. Rats or mice inoculated with vehicle (saline) served as controls $(n=6)$. In another set of experiments, animals were randomized and divided into four groups, namely controls $(C, n=6)$ and C26 $(n=8)$, treated or not with insulin (INS). INS groups received daily i.p. injections of insulin (1,5 IU/kg b.w.) during the whole experimental period. For 'autophagic flux' experiments controls $(C, n=6)$ and C26 $(n=6)$ mice were either administered colchicine $0,4 \mathrm{mg} / \mathrm{kg} /$ day or vehicle for two days before sacrifice (both day 11 and day 14 of tumor growth). Dexamethasone (Dexa) was administered i.p. daily for 7 days to 6 week old Balb-c mice $(\mathrm{n}=8)$ at the dose of $1 \mathrm{mg} / \mathrm{kg}$. Vehicle (saline containing $5 \%$ ethanol)-treated mice served as controls ( $n=6)$. Animal weight and food intake were recorded daily. Tumor-bearing rats and mice were sacrificed under anesthesia 7 and 14 days after tumor transplantation, respectively. Several muscles and organs were rapidly excised, weighed, frozen in isopentane cooled with liquid nitrogen and stored at $-80^{\circ} \mathrm{C}$. As for calorie restriction (CR), 6 month-old rats were either fed ad- 
1 libitum (AL) or given $60 \%$ (w/w; $40 \%$ CR) of the food consumed by AL animals until 24 months of age. As for the in vivo TNF administration, C57/BL6 mice weighing about $20 \mathrm{~g}$ received an intramuscular injection of TNF as previously reported $\left(40 \mu \mathrm{g} / \mathrm{kg}\right.$ body weight $\left.{ }^{28,29}\right)$ in the right gastrocnemius and were sacrificed after $12 \mathrm{~h}$. Saline treated mice in place of using the contralateral muscle served as control in order to exclude TNF-dependent systemic effects.

\section{Insulin Tolerance Test}

Control, C26 and C26 INS-treated mice at day 11 of tumor growth were challenged with insulin (1,5 IU/kg b.w., i.p.). A blood drop was collected by saphenous vein puncture before, 15, and 45 min. after insulin administration and glycemia was measured using the Glucocard G-sensor strips and apparatus (Menarini Diagnostics). Glycemia was also assessed before sacrifice collecting the blood by cardiac puncture from anesthetized animals in order to assess the relationship between glycemia and body weight changes. Correlation was calculated according to Pearson's.

\section{Cell cultures}

Murine C2C12 skeletal myoblasts (ATCC) were grown in high glucose DMEM supplemented with $10 \% \mathrm{FBS}, 100 \mathrm{U} / \mathrm{ml}$ penicillin, $100 \mu \mathrm{g} / \mathrm{ml}$ streptomycin, $100 \mu \mathrm{g} / \mathrm{ml}$ sodium pyruvate, $2 \mathrm{mM} \mathrm{L-}$ glutamine, and maintained at $37^{\circ} \mathrm{C}$ in a humidified atmosphere of $5 \% \mathrm{CO} 2$ in air. Differentiation was induced by shifting sub-confluent cultures to DMEM supplemented with $2 \%$ horse serum (differentiation medium; DM). At the same time, the cells were exposed to TNF $\alpha(100 \mathrm{ng} / \mathrm{ml}$ ) or to INS (10ug/ml), or both, and collected after $48 \mathrm{~h}$; untreated cells served as control. Such differentiation scheme was chosen after a preliminary screening of the TNF $\alpha$-dependent autophagy induction in growing myoblasts, differentiating ( 2 days) or fully differentiated (6 days) myotubes. The differentiating cells showed the strongest autophagy alterations (data not shown) and were adopted for the following experiments. In a different set of experiments TNF $\alpha$ action was also tested at a lower dose $(5 \mathrm{ng} / \mathrm{ml})$ in fully differentiated myotubes. For 'autophagic flux' measurements, $200 \mathrm{nM}$ Bafilomycin A1 was added 6 hours before the termination of the experiments, as previously reported ${ }^{30}$. As for the data showed in Figure S6, at the time of shifting sub-confluent cultures to differentiation medium, the cells were exposed to a stable IGF-1 synthetic peptide (LONG-R3IGF-I, Sigma $85580 \mathrm{C}, 50 \mathrm{ng} / \mathrm{ml}$ ) or to neutralizing anti-IGF-1 antibody (Sigma 18773), in the presence or in the absence of TNF $\alpha(100 \mathrm{ng} / \mathrm{ml})$ and collected after $48 \mathrm{~h}$; untreated cells served as control.

Primary satellite cells 
Single muscle fibers with associated satellite cells were isolated from the tibialis anterior muscles after digestion with collagenase. Single myofibers were plated on matrigel-coated dishes in DMEM supplemented with $20 \%$ FBS, $10 \%$ horse serum, $0.5 \%$ chick embryo extract and penicillin-streptomycin. Three days later the medium was replaced with proliferation medium (DMEM 20\% FBS, 10\% horse serum, 1\% chick embryo extract) to promote proliferation of detached cells (delaminated satellite cells). After 5 days (only satellite cells remain on the plate), the medium was replaced with differentiation medium ( $2 \%$ horse serum and $0.5 \%$ chick embryo extract in DMEM).

\section{Western blotting}

About $50 \mathrm{mg}$ of gastrocnemius muscle were homogenized in $80 \mathrm{mM}$ Tris- $\mathrm{HCl}, \mathrm{pH} 6.8$, containing $100 \mathrm{mM}$ DTT, $70 \mathrm{mM}$ SDS, and $1 \mathrm{mM}$ glycerol, with freshly added protease and phosphatase inhibitor cocktails, kept on ice for $30 \mathrm{~min}$, centrifuged at $15000 \times \mathrm{g}$ for $10 \mathrm{~min}$ at $4^{\circ} \mathrm{C}$, and the supernatant collected. Protein concentration was assayed using BSA as working standard. C2C12 cells were lysed on RIPA buffer (50 mM Tris- $\mathrm{HCl} \mathrm{pH} \mathrm{7.4,} 150 \mathrm{mM} \mathrm{NaCl}, 1 \%$ NP40, $0.25 \% \mathrm{Na}-$ deoxycholate, $1 \mathrm{mM}$ PMSF) with freshly added protease and phosphatase inhibitor cocktails. Equal amounts of protein $(30 \mu \mathrm{g})$ were heat-denaturated in sample-loading buffer $(50 \mathrm{mM}$ Tris- $\mathrm{HCl}, \mathrm{pH}$ 6.8, $100 \mathrm{mM}$ DTT, 2\% SDS, $0.1 \%$ bromophenol blue, 10\% glycerol), resolved by SDS-PAGE and transferred to nitrocellulose membranes (Bio-Rad). The filters were blocked with Tris-buffered saline (TBS) containing $0.05 \%$ Tween and $5 \%$ non-fat dry milk and then incubated overnight with antibodies directed against: Beclin1 (Sigma B6186), LC3B (Sigma L7583), p62 (BD Biosciences 610832), p-Akt (Ser473; Cell Signaling Technology 9271), atrogin-1 (ECMbiosciences AP2041) and tubulin (Sigma T5168). Peroxidase-conjugated IgG (Bio-Rad) was used as secondary antibodies. Quantification of the bands was performed by densitometric analysis using a specific software (TotalLab, NonLinear Dynamics, Newcastle upon Tyne, UK).

\section{Reverse transcription-PCR}

Total RNA was obtained using the TriPure reagent (Roche) following manufacturer's instructions. RNA concentration was determined fluorometrically using the Ribogreen reagent (Invitrogen). RNA integrity was checked by electrophoresis on $1.2 \%$ agarose gel, containing morpholino propane-sulfonic acid (MOPS) $0.02 \mathrm{M}$ and 18\% formaldehyde. Total mRNA was retrotranscribed using the i-Script cDNA synthesis kit (Bio-Rad). Transcript levels were determined by real-time PCR using the SsoFast Evagreen Supermix and the MiniOpticon thermal cycler (Bio-Rad). 
1 Primer sequences were as follows: Atrogin1 FW-agcgacctcagcagttactgc, RW-cttctggaatccaggatggc; Beclin1 FW-tgaatgaggatgacagtgagca, RW-cacctggttctccacactcttg; Cathepsin L FWgtggactgttctcacgctcaag, RW-tccgtccttcgcttcatagg; LC3B FW-cactgctctgtcttgtgtaggttg, RWtcgttgtgcctttattagtgcatc; p62 FW-cccagtgtcttggcattctt, RW-agggaaagcagaggaagctc; NBR1 FWccccagattggtttacaagc, RW-tccaccgtttccttaaccac.

\section{Cathepsin enzymatic activity}

Cathepsin $B+L$ activity was determined by evaluating the cleavage of a specific chromogenic substrate (see 50). $50 \mathrm{mg}$ of gastrocnemius muscle were homogenized in 0,25 M sucrose, $25 \mathrm{mM}$ Hepes pH 7.4, $2 \mathrm{mM}$ EDTA, and then centrifuged at $2000 \mathrm{~g}$ for $5 \mathrm{~min}$ at $4{ }^{\circ} \mathrm{C}$. The supernatant was collected and centrifuged at $70000 \mathrm{~g}$ for $30 \mathrm{~min}$ at $4{ }^{\circ} \mathrm{C}$. The pellet was suspended in 0,1 M Na-acetate pH 5.5, 1 mM EDTA. Aliquots of $10 \square$ g protein wes incubated for $60 \mathrm{~min}$ at 37 ${ }^{\circ} \mathrm{C}$ in the presence of $100 \mu \mathrm{M}$ substrate (Z-Phe-Arg-p-Nitroanilide, Enzo Life Sciences). The incubation buffer was 0,5 M Na-acetate pH 5.5, 5 mM DTT, 2,5 mM EDTA. Absorbance was read with a spectrophotometer at $410 \mathrm{~nm}$ (Perkin-Elmer) using free p-Nitroanilide as working standard.

\section{Immunofluorescence}

C2C12 monolayers were washed with PBS and fixed in acetone-methanol (1:1). Samples were then probed with the following primary antibodies: LC3B (Sigma L7543), p62 (BD Biosciences 610832). Detection was performed using a FITC-conjugated rabbit IgG secondary antibody. Nuclei were stained with the Hoechst 33342 fluorochrome and the images captured in an epiilluminated fluorescence microscope (Axiovert 35, Zeiss).

\section{Data analysis and presentation}

All results were expressed as mean $\pm S D$, with the exception of gene expression (mean \pm SEM). Representative western blots show independent samples. Significance of the differences was evaluated by analysis of variance (ANOVA) followed by Tukey's test. 
RESULTS

- Autophagy is induced in C26-bearing mice

The C26 colon carcinoma induces progressive loss of body and muscle weight (see Supplemental Figure S1A and S1B at http://ajp.amjpathol.org). Muscle expression of proteins accepted as markers of autophagy has been assessed in the gastrocnemius muscle at both days 11 and 14 of tumor growth, representing initial and advanced stage of muscle wasting, respectively. Beclin-1, a main upstream regulator of autophagic sequestration ${ }^{31}$, is markedly increased already at day 11 , suggesting that autophagy activation is an early event in tumor-induced muscle depletion (Fig. 1A). Secondly, levels of microtubule-associated protein 1 light chain 3B isoform I (LC3B-I) do not change in tumor-bearing mice, while the lipidated form (LC3B-II), a reliable marker of autophagosome formation ${ }^{30}$, is significantly elevated at both experimental time points (Fig. 1A). Moreover, the levels of p62/SQSTM1 have been assayed as a measure of substrate sequestration into autophagosomes; p62, indeed, binds LC3 as well as substrates marked for degradation by ubiquitylation ${ }^{30}$. Similarly to beclin-1 and LC3B-II, p62 accumulates at both experimental points (Fig. 1A), which could reflect either induction of autophagic sequestration or reduced autophagosome clearance ${ }^{32}$. To clarify this point, a flux experiment was performed by treating both controls and C26 hosts with colchicine, a microtubule-destabilizing agent that interacts with tubulin ${ }^{33}$. The results show that LC3B-II levels, already higher than in controls in the C26 hosts, further increase after colchicine administration (Fig. 1B), demonstrating that autophagy is indeed activated. The reduction of tubulin expression in colchicine-treated animals (Fig. 1B) vs. untreated mice likely reflects specific drug-induced degradation ${ }^{34}$, demonstrating that the treatment protocol adopted leads to bioactive colchicine levels in the skeletal muscle. Despite the flux experiment was designed in order to achieve data for both days 11 and 14 of tumor growth, only the first time-point could be evaluated; indeed, tumor-bearing animals administered colchicine on days 12 and 13 did not reach day 14 and died before sacrifice.

The possibility that also reduced autophagosome clearance might occur in the present experimental setting cannot be discarded, however. A gene study shows that p62 transcript is increased at day 14 of tumor growth (Fig. 2A), while the enzymatic activity of lysosomal cathepsins is reduced at day 14, though not at day 11 (Fig. 2B), suggesting that p62 accumulation may result from transcriptional induction and, possibly, reduced degradation. The gene study also gives evidence for increased levels of mRNAs coding for atrogin-1, cathepsin L, LC3B and NBR1, a 
protein with functional similarity to p62 (Fig. 2A), further supporting the occurrence of a sustained induction of autophagy. Notably, autophagy induction in C26-bearing mice is not a feature specific for the skeletal muscle, being also detectable in the liver, wherein the pattern of LC3B and p62 expression is comparable to that observed in the gastrocnemius (see Supplemental Figure S2A at http://ajp.amjpathol.org).

\section{- Autophagy is not a specific feature of the C26 hosts}

To assess if the enhanced autophagic degradation is peculiar to C26-bearing mice or also occurs in other experimental models of cancer cachexia, autophagic markers have been evaluated in the gastrocnemius muscle of rats bearing the Yoshida $\mathrm{AH}-130$ hepatoma or of mice transplanted with the Lewis lung carcinoma (LLC). As for the former, muscle depletion induced by 7 days of tumor growth (Fig. 3A) is associated with both increased LC3B lipidation (LC3B-II) and p62 accumulation, while no changes in beclin-1 levels occur (Fig. 3B). On the other side, muscle wasting in LLC hosts (Fig. 3C) is characterized by up-regulation of beclin-1 and p62 (Fig. 3D).

These observations indicate that, though with different pattern, autophagy is activated in all the experimental models of cancer cachexia analyzed. In this regard, these results provide the first comprehensive approach to the contribution of autophagy to the pathogenesis of skeletal muscle wasting in cancer cachexia, confirming but significantly extending previous observations (see Introduction and Discussion). In addition, these result support the idea that a single marker is not sufficient to depict the state of activation of the autophagic-lysosomal degradative system ${ }^{30}$.

\section{- Activation of autophagy in cancer-unrelated muscle wasting}

To investigate whether the modulations of autophagy in cancer-related muscle atrophy are comparable to those observed in other conditions associated with muscle wasting, autophagic markers were analyzed in dexamethasone (Dexa)-induced muscle atrophy and in aging-related sarcopenia.

Dexamethasone Mice received daily i.p. injections of Dexa, a synthetic glucocorticoid whose catabolic action has been thoroughly investigated ${ }^{23}$. Body and muscle weight loss induced by Dexa administration (7 days; Fig. 4A) are associated with increased expression of beclin-1 and both LC3B isoforms, while p62 virtually disappears (Fig. 4B). The different pattern of p62 expression in Dexa-treated mice compared to that observed in tumor-bearing animals is associated with lack of p62 transcriptional induction (Fig. 4C) as well as with normal cathepsin enzymatic activity (Fig. 4D). The gene study also shows an increased expression of atrogin-1, cathepsin L and NBR1 (Fig. 4C). 
1 These observations are in line with previous data reporting that autophagy significantly contributes to muscle wasting in different experimental conditions, such as denervation, starvation and sepsis ${ }^{10,20}$. Not only, while providing a panel of autophagy markers (at both gene and protein levels), the present results show that an efficient autophagosome clearance is achieved in the muscle of glucocorticoid-treated animals, as inferred by the markedly reduced p62 levels.

Aging Both cancer and glucocorticoids induce muscle depletion in the short period (7-14 days, depending on the model), and can thus be considered as 'acute' wasting conditions. On the contrary, sarcopenia associated with aging is a chronic state and the underlying mechanisms could be different. To test the relevance of autophagy to sarcopenia, the same markers reported above have been measured in aged mice and rats. In 22 month old mice both beclin-1 and LC3B-I protein levels fall, while p62 markedly accumulates in comparison with 3 month old mice (Fig. 5A), suggesting a reduced autophagic degradation. As for the rats, the comparison between 6 and 24 month old animals shows the accumulation of p62 (Fig. 5B). In the attempt to stimulate the autophagic flux, rats have been submitted to $40 \%$ calorie restriction, an anti-aging strategy previously shown to activate liver autophagy ${ }^{35}$. In the present conditions, calorie restriction reduces both LC3B-II and p62 levels in the skeletal muscle, likely releasing the autophagy blockade (Fig. 5B).

\section{- Autophagy in cancer-induced muscle atrophy is only partially modulated by insulin}

Autophagy is mainly regulated by the PI3K/Akt/mTOR (mammalian Target of rapamycin) pathway and previous data showed that insulin administration effectively prevented muscle protein hypercatabolism in rats bearing the $\mathrm{AH}-130$ hepatoma ${ }^{14}$. To test if insulin effectiveness in preventing muscle wasting could rely on down-regulation of the autophagic degradation, the hormone was administered to C26-bearing mice, the model system where autophagy appears more marked. In contrast with the results previously obtained in the AH-130 hosts ${ }^{14}$, insulin administration does not attenuate cachexia in the C26 hosts (Fig. 6A). Beclin-1 and p62 protein levels in insulin-treated tumor hosts are reduced in comparison to the untreated animals, but remain significantly higher than in controls, demonstrating that insulin inhibition of autophagy is far from being complete (Fig. 6B). Such a pattern is not peculiar to the skeletal muscle, since comparable results can be observed in the liver (see Supplemental Figure S2B at http://ajp.amjpathol.org). The gene study analysis shows that atrogin-1, beclin-1 and p62 
transcripts are reduced by insulin, while cathepsin L and LC3B are even increased (Fig. 6C). The partial restoration of physiological autophagy exerted by insulin could reflect a condition of mild resistance to this hormone. In this regard, a study reported in the literature suggests that muscle wasting in $\mathrm{C} 26$ hosts is associated with insulin resistance ${ }^{17}$. To clarify this point, an insulin tolerance test has been performed. The results show that both control and tumor-bearing animals, either treated with insulin or not, respond comparably to insulin challenge, thus excluding the occurrence of insulin resistance (see Supplemental Figure S3B at http://ajp.amjpathol.org). In addition, the direct correlation existing between basal glycemia and body weight changes over the experimental period (see Supplemental Figure S3C at http://ajp.amjpathol.org), suggests that, at least in this experimental setting, hypoglycemia rather than insulin resistance contributes to the loss of body weight.

\section{- TNF $\alpha$ directly stimulates autophagic degradation in skeletal muscle cell cultures.}

Muscle wasting in cancer cachexia is largely mediated by proinflammatory cytokines. Indeed, protein hypercatabolism can be partially reversed by treating rats bearing the $\mathrm{AH}-130$ hepatoma with anti-TNF $\alpha$ antibodies or with pentoxifylline, an inhibitor of TNF $\alpha$ synthesis ${ }^{36,37}$. We examined whether TNF $\alpha$ has the ability to directly activate the autophagic process in differentiating $\mathrm{C} 2 \mathrm{C} 12$ myocytes cultured in the presence of the cytokine for 48 hours. Similarly to a previous study obtained with the cytokine TWEAK (TNF-like weak inducer of apoptosis) ${ }^{38}$, TNF $\alpha$ causes a reduction of Akt phosphorylation (Fig. 7A). This observation seems in contrast with previous data showing increased levels of phosphorylated Akt in TNF $\alpha$-treated C2C12 myotubes ${ }^{39}$; the discrepancy may well result from the fact that the experiments here shown were performed on differentiating $\mathrm{C} 2 \mathrm{C} 12$ myocytes (see Materials and Methods). The reduced levels of active Akt are associated with beclin-1 induction and LC3B-II accumulation (Fig. 7A), in the absence of significant changes of atrogin-1 expression ( $C=0.55 \pm 0.15, T N F=0.39 \pm 0.15$, a. $u ., n=3)$. Activation of autophagy is also suggested by the increased p62 (Fig. 7B) and dotted LC3B staining (C $=4 \pm 2$, TNF $=41 \pm 9$, cells with more than 10 puncta $/ 60$ nuclei, $n=3, p=0.0024 ;$ Fig. $8 B$ ). A comparable pattern can be observed also in primary satellite cells exposed to TNF $\alpha$ (see Supplemental Figure S4A at http://ajp.amjpathol.org), as well as in C2C12 myotubes exposed to low TNF $\alpha$ concentrations ( $5 \mathrm{ng} / \mathrm{ml}$; see Supplemental Figure S4B at http://ajp.amjpathol.org). Finally, 'autophagic flux' was evaluated by incubating C2C12 cultures with bafilomycin $\mathrm{A} 1$, a drug able to inhibit the vacuolar $\mathrm{H}^{+}$-ATPase, resulting in reduced acidification and, therefore, lysosomal- 
1 dependent degradation of the autophagosome cargo ${ }^{33}$. The results show that LC3B-II levels in bafilomycin A1-treated cells markedly increase with respect to controls. When cultures are exposed to TNF $\alpha$ and bafilomycin A1, LC3B-II levels are significantly higher than those measured in cells treated with bafilomycin A1 alone (Fig. 8A, see Supplemental Figure S4B at http://ajp.amjpathol.org). This observation suggests that the rate of LC3B-II formation is increased by the cytokine $\left(\right.$ see $^{40}$ ). Conversely, LC3B-II levels in C2C12 cultures treated with TNF $\alpha$ alone (100 ng/ml, Fig. 8A) are not different from those detected in cells exposed to TNF $\alpha$ and bafilomycin A1. Such an observation would suggest that TNFa inhibits autophagosome degradation rather than enhancing their formation. However, lysosomal proteolysis should be completely blocked by bafilomycin; on this line, LC3B-II increase over bafilomycin-induced levels should result from enhanced autophagosome formation ${ }^{40}$. This conclusion is strengthened by the results obtained on C2C12 myotubes exposed to TNF $\alpha 5 \mathrm{ng} / \mathrm{ml}$ (Fig. S4B). In this regard, the results obtained on C2C12 cells are on the same line of those reported for the muscle of the C26 hosts, where both inhibition of autophagosome degradation and increased sequestration are likely to occur. To ascertain if autophagy can be activated by TNF $\alpha$ also in vivo, healthy mice received an intramuscular injection of this cytokine $\left(40 \mu \mathrm{g} / \mathrm{kg}\right.$ body weight $\left.{ }^{28,29}\right)$ and were sacrificed $12 \mathrm{~h}$ later. Figure S5 (available at http://ajp.amjpathol.org) shows that LC3B-II levels are increased in TNF $\alpha$-treated muscles in comparison to the muscle of control mice, the more so when the animals also received colchicine, indicating the enhancement of autophagic flux.

The data reported above indicate that exposure of muscle cell cultures to TNFa results in upregulation of autophagy. To clarify if this effect is responsive to anabolic regulation, C2C12 cells were cotreated with TNF $\alpha$ and insulin. As expected, the results show that insulin alone increases Akt phosphorylation $(C=0.21 \pm 0.05$, INS $=0.31 \pm 0.03$, a. u., $n=3, p<0.05)$ and reduces both atrogin-1 expression ( $C=0.55 \pm 0.15$, INS $=0.28 \pm 0.05$, a. u., $n=3, p<0.05$ ) and LC3B-II levels (Fig. 7A). These observations, together with the enhanced immunostaining for p62 (Fig. 7B), suggest that basal autophagy is inhibited. When insulin is coupled to TNF $\alpha$, no significant changes could be observed as for atrogin-1 expression (INS $=0.28 \pm 0.05$, INS+TNF $=0.24 \pm 0.06$, a. $u ., n=3$ ) and Akt phosphorylation (INS $=0.31 \pm 0.03$, INS $+T N F=0.18 \pm 0.10$, a. u., $n=3 ;$ Fig. $7 \mathrm{~A}$ ), although a tendency to reduction is apparent. Despite insulin exposure, both TNF $\alpha$-induced beclin-1 and LC3B-II increase remain detectable (Fig. 7A). In the presence of bafilomycin A1, insulin results in LC3B-II accumulation lower than in cells exposed to the lysosomal inhibitor alone (Fig. 8B). However, in 
1 insulin and bafilomicyn A1 treated cultures, LC3B-II levels in the presence of TNF $\alpha$ are higher than

2 those observed in the absence of the cytokine, although they do not reach those obtained in cells

3 exposed to bafilomycin A1 alone (Fig. 8B). Such observation suggests that insulin reduces basal

4 autophagic flux but is unable to completely prevent the activation induced by TNF $\alpha$ exposure. This

5 hypothesis is confirmed by LC3B immunostaining (INS $=5 \pm 1, T N F+I N S=60 \pm 9$, cells with more

6 than 10 puncta/60 nuclei, $n=3, p=0.00025$; Fig. 7B). Similar results have been obtained by

7 treating the cells with recombinant stable IGF1, while treatment with an IGF1 neutralizing

8 antibody is sufficient to activate autophagy, although to levels lower than those attained by TNF $\alpha$

9 (see Supplemental Figure S6A and S6B at http://ajp.amjpathol.org). 


\section{DISCUSSION}

The present study demonstrates that muscle wasting in three different experimental models of cancer cachexia is associated with increased autophagy, as evaluated by analyzing three among the most representative markers of this degradative pathway: beclin-1 as an indicator of autophagy induction, LC3B conversion to the lipidated form to measure autophagosome abundance and p62/SQSTM1 as a marker of substrate sequestration and eventual degradation (see Results). The analysis of these proteins gives an approximate estimate of the autophagic flux, i.e. the extent of protein sequestration and subsequent degradation into lysosomes. To further strengthen the data, autophagic flux was measured by treating C26 hosts with colchicine (see ${ }^{33}$ ). Although the markers of autophagy mentioned above do not strictly share the same pattern of expression in the cachexia models used in the present study, the net result is that in all of them an increase of autophagic degradation is likely to occur. This observation represents an important new finding. Indeed, while muscle wasting in cancer cachexia is considered to depend mainly on hyperactivation of proteasomal degradation ${ }^{2,41-44}$, only recently beclin-1 and LC3B induction was shown in LLC-bearing mice ${ }^{8}$, while Bnip3 overexpression or increased LC3B-II levels in the C26 hosts were previously reported ${ }^{17,18}$. Finally, autophagy was proposed to contribute to C26induced cardiac atrophy ${ }^{19}$.

To the best of our knowledge, the data shown in the present study represent the most comprehensive analysis actually available showing how the autophagic system is poised towards activation in the skeletal muscle of the C26-bearing mice. Similar conclusions can be drawn from results obtained in rats bearing the $\mathrm{AH}-130$ Yoshida hepatoma, where hyperactivation of muscle Iysosomal proteases was already shown by Tessitore et al. ${ }^{13}$, and in mice implanted with the LLC tumor, these latter confirming but extending what previously reported by Paul and coworkers ${ }^{8}$. These results highlight the relevance of autophagy to cancer-induced muscle wasting, the more so when considering that not only the upstream signals that activate protein breakdown are able to coordinate both autophagy and proteasome induction ${ }^{45,46}$, but also that typical proteasome substrates (e.g. ubiquitylated proteins) can be alternatively degraded through the acidic vacuolar proteolysis ${ }^{47}$.

A careful analysis of the results here presented suggests that, despite autophagy is activated in both cancer cachexia and dexametasone-induced muscle atrophy, but not in sarcopenic muscles, different mechanisms are operating in the specific experimental conditions. 
1 As for cancer cachexia, all the markers of autophagy are up-regulated in the C26 hosts. Particularly interesting in this regard is the marked accumulation of p62, that contrasts with the observation that autophagic flux is clearly enhanced, at least in d11 C26 hosts (see Fig. 1B). Such increased p62 levels could reflect a transcriptional induction, as reported in desmin-related cardiomyopathy ${ }^{48}$. Consistently, p62 gene expression is markedly increased in the muscle of the C26 hosts.

Autophagic flux measurement was not possible in day 14 C26 hosts, since colchicine-treated animals died before sacrifice, suggesting that autophagy inhibition negatively impinges on survival when the metabolic homeostasis is markedly compromised.

Despite the induction of autophagy, muscle lysosomal cathepsin activities are reduced in day 14 C26 bearers, a finding that may reflect selective disturbances in lysosomal function, such as lysosomal enzyme mistargeting ${ }^{49}$. In this regard, the possibility that during tumor growth muscle protein degradation relies initially on the lysosomal system and only subsequently on other proteolytic pathways cannot be excluded. Consistently, lysosomal protease activity is reduced only in day 14 C26 hosts (advanced cachexia), in parallel with both increased atrogin-1 mRNA levels and calpastatin degradation, this latter being a marker of calpain hyperactivation (unpublished data).

As for dexamethasone-induced atrophy, the results show that both beclin-1 and LC3B-II increase, while p62 virtually disappears, indicating that substrates sequestered into autophagosomes are readily degraded by lysosomes. The lack of p62 accumulation in the skeletal muscle of dexamethasone-treated mice is associated with unchanged levels of p62 transcript. In addition, this observation suggests that even if rapid muscle atrophy observed in both tumor bearers and glucocorticoid-treated mice is characterized by autophagic degradation, the molecular signals involved are different and may require distinct therapeutic approaches.

Finally, autophagic degradation is reduced in the skeletal muscle of aged animals while is reactivated by $\mathrm{CR}$, consistently with recent data ${ }^{26}$. Reduced muscle mass occurs in both aging and $\mathrm{CR}^{50}$, however the pattern of the autophagic markers is quite different. Indeed, while in aged animals both beclin-1 and LC3B-II are comparable, or even reduced vs. young individuals, p62 levels are markedly increased, likely because autophagy is not activated, and waste substrates accumulate. While impairment of autophagic degradation during aging is a well known event in the liver, the present observations represent a new finding, since very few data are actually available as for the skeletal muscle ${ }^{26}$. In this regard, abnormal mitochondria and sarcomere disorganization in aged skeletal muscle likely results from impaired autophagy. Consistently, 
muscle-specific deletion of Atg7, a crucial autophagy gene, leads to phenotypic alterations resembling sarcopenia ${ }^{51}$. As for $\mathrm{CR}$, it is associated with $\mathrm{p} 62$ levels that are still increased with respect to young animals, but markedly reduced in comparison to aged rats, suggesting a partial restoration of the autophagic flux. These observations are in agreement with a previous report by Wohlgemuth et al. ${ }^{26}$, showing that $8 \%$ calorie restriction was able to partially restore the reduced expression of autophagic markers in aged rats.

In the C26 host, energy deficit, whose occurrence is suggested by the correlation between hypoglycemia and body weight loss as well as by mitochondrial damage (Penna et al., unpublished data), is a possible trigger of autophagy, not only in the skeletal muscle, but also in the liver ${ }^{52}$. Such a speculation would fit with the recently proposed model of "battery-operated tumor growth", where autophagic degradation is suggested to start in the tumor stroma and then to spread systemically in order to provide a continuous energy transfer from the host to the tumor ${ }^{53}$. The onset of cancer cachexia is also associated with a proinflammatory environment ${ }^{54,55}$. In this regard, anti-TNF $\alpha$ strategies have been shown to effectively prevent the hyperactivation of proteasomal degradation in the $\mathrm{AH}-130$ hosts ${ }^{36,37}$. Recent data show that TRAF6 induces the expression of muscle-specific E3 ubiquitin ligases and autophagy-related molecules in the skeletal muscle upon denervation and in LLC-bearing mice ${ }^{8}$. Moreover, TWEAK has been reported to induce the activation of both autophagy and proteasome in $\mathrm{C} 2 \mathrm{C} 12$ myotubes ${ }^{56}$. The results obtained in the present study show that TNF $\alpha$ directly stimulates autophagic degradation in both C2C12 and isolated murine satellite cells, suggesting another possible trigger of autophagy in cancer cachexia.

A relevant issue raised in the present work concerns the observation that TNF $\alpha$ exposure in vitro, as well as tumor growth in vivo, partially overcome the well known insulin/IGF-1 ability to down-regulate autophagy. These results could explain the virtual lack of effect of IGF-1/insulinbased strategies in preventing cancer-induced muscle wasting $\left({ }^{57,58}\right.$; present work). In this regard, a quite recent study reported that increased IGF-1 receptor engagement in the skeletal muscle results in rapid IRS-1 phosphorylation and proteasome-dependent degradation ${ }^{59}$. On the contrary, IGF-1 overexpression effectively prevents glucocorticoid-induced muscle atrophy as well as the sarcopenia of aging ${ }^{22,57}$, although no information regarding the effect on autophagy in these model systems are actually available.

\section{Conclusions}


The results reported in the present study show that autophagy contributes to generate

2 muscle atrophy in cancer cachexia as well as in dexamethasone-treated animals, although the 3 underlying mechanisms in the two conditions are likely different. By contrast, sarcopenia of aging, 4 a slow but progressive physiological loss of muscle mass, does not seem to depend on autophagy.

5 These results further support the idea that the final event, e.g. muscle wasting, likely derives from 6 the combination of different mechanisms; in this regard, autophagy participates to variable extent 7 to the complicated network that leads to the loss of muscle mass. Finally, catabolic stimuli such as 8 the presence of a tumor or, more specifically, proinflammatory cytokines, cannot be fully 9 antagonized, at least in terms of autophagic degradation, by insulin, one of the most powerful 10 inhibitors of autophagy. These results are particularly intriguing, and could suggest that activation 11 of autophagy in these model systems is so enforced that cannot be circumvented by simple 12 inhibitor-based strategies. 
Figure 1. Densitometric analysis and representative patterns of expression of autophagy-related proteins in the GSN muscle of $C$ and $C 26$ bearers at 11 or 14 days after tumor transplantation (A). Densitometric analysis and representative patterns of expression of LC3B protein in the gastrocnemius of $\mathrm{C}$ and C26 hosts at day 11 of tumor growth either untreated or treated with colchicine (Col; B). Data (mean \pm SD) are expressed as percentages of C. Significance of the differences: ${ }^{*} p<0.05$ vs $C,{ }^{* *} p<0.01$ vs $C,{ }^{* *} p<0.001$ vs $C, \# \# p<0.01$ vs Col, $\$ \$ p<0.01$ vs C26.

Figure 2. Expression of genes involved in atrophy (A) and cathepsin $B+L$ activity (B) in the GSN of $C$ and C26 hosts at day 14 and 11 of tumor growth. Data (mean \pm SD) are percentages of C. As for gene expression results are expressed as mean \pm SEM. Significance of the differences vs C: ${ }^{*} p<0.05, * * p<0.01, * * * p<0.001$.

Figure 3. Gastrocnemius muscle mass and expression of autophagy-related proteins in GSN of AH$130(\mathrm{~A}, \mathrm{~B})$ or LLC tumor-bearing animals (C, D). Data (mean \pm SD) are expressed as percentages of C. Significance of the differences vs $C:{ }^{*} p<0.05,{ }^{* *} p<0.01,{ }^{* * *} p<0.001$.

Figure 4. Loss of body weight and skeletal muscle mass in dexamethasone-treated mice $(A ; G S N=$ gastrocnemius, TIB = tibialis). Densitometric analysis and representative patterns of expression of autophagy-related proteins in the GSN muscle of $C$ and DEXA-treated mice (B). Expression of genes involved in atrophy $(C)$ and cathepsin $B+L$ activity $(D)$ in the GSN of $C$ and DEXA-treated mice. Data (mean $\pm S D$ ), are percentages of $C$. As for gene expression results are expressed as mean \pm SEM. Significance of the differences vs $\mathrm{C}:{ }^{*} \mathrm{p}<0.05,{ }^{* *} \mathrm{p}<0.01,{ }^{* *} \mathrm{p}<0.001$.

Figure 5. Densitometric analysis and representative patterns of expression of autophagy-related proteins in the gastrocnemius (GSN) of 3 and 22 month old mice (A) and 6 or 24 months old rats (B), fed ad libitum (AL) or with $40 \%$ calorie restriction (CR). Data (mean $\pm S D$ ), are percentages of C. Significance of the differences vs C: ${ }^{*} p<0.05,{ }^{*} p<0.01, * * * p<0.001 ;$ vs AL24: $\$ p<0,05$.

Figure 6 . Loss of body weight and skeletal muscle mass in insulin-treated (1,5 IU/kg b.w.) animals $(\mathrm{A} ; \mathrm{GSN}=$ gastrocnemius, $\mathrm{TIB}=$ tibialis). Densitometric analysis and representative patterns of expression of autophagy-related proteins in the GSN muscle of $C$ and C26 hosts, either treated or untreated with insulin (B). Expression of genes involved in atrophy in the GSN of C, C26 and INStreated $\mathrm{C} 26$ hosts $(C)$. Data (mean \pm SD), are percentages of $C$. As for gene expression, results are 
1 expressed as mean \pm SEM. Significance of the differences vs C: ${ }^{*} p<0.05,{ }^{* * *} p<0.001$; vs C26 $2 \quad \$ p<0.05, \$ p<0.01$.

3 Figure 7. C2C12 myotubes (2 day differentiation) treated for $48 \mathrm{~h}$ with $\mathrm{TNF} \alpha$, in the presence or in

4 the absence of INS. Densitometric analysis and representative patterns of expression of autophagy

5 related proteins and of phospho-Akt $(A)$. Data (mean $\pm S D ; n=3$ ) are expressed as percentages of controls. Significance of the differences: ${ }^{*} p<0.05$ vs $C,{ }^{* *} p<0.01$ vs $C ; \S p<0.05$ vs TNF $\alpha$. (B) $p 62$ and LC3B immunostaining (green: p62 or LC3B-II; blue: HOECHST).

Figure 8. Densitometric analysis of expression of autophagy related proteins in $\mathrm{C} 2 \mathrm{C} 12$ cells cultured in the presence or in the absence of bafilomycin A1 (BAF; A) and/or insulin (B). Data (mean $\pm S D ; n=3$ ) are expressed as percentages of controls. Significance of the differences: ${ }^{*} p<0.05$ vs $C,{ }^{*} p<0.01$ vs $C ; \# p<0,05$ vs BAF; $\$ p<0.05$ vs BAF INS.

\section{SUPPLEMENTAL FIGURE LEGENDS}

Figure S1. Loss of body (A) and skeletal muscle weight (B; GSN = gastrocnemius, $\mathrm{TIB}=$ tibialis) in Controls and $\mathrm{C} 26$ hosts $(C=6, C 26=8)$ at day 11 and 14 of tumor growth.

Figure S2. Densitometric analysis and representative patterns of expression of autophagy-related proteins in the liver of $\mathrm{C}$ and $\mathrm{C} 26$ hosts (A), or C, C26 bearers and INS-treated C26 hosts (B) at day 14 of tumor growth. Data (mean \pm SD) are expressed as percentages of C. Significance of the differences vs $C:{ }^{*} p<0.05, * * p<0.01, * * * p<0.001$; vs C26: $\$ p<0.01$.

Figure S3. Daily food intake (A) and insulin tolerance test (B) in C, C26 and INS-treated C26 hosts. Correlation between glycemia and $\Delta$ i.b.w. in C26 hosts, either untreated ( $r=0.693)$ or INS-treated $21 \quad(r=0.939 ; C)$.

Figure S4. (A) LC3B immunostaining in primary cultures of tibialis-derived satellite cells untreated or treated for $48 \mathrm{~h}$ with TNFa $(100 \mathrm{ng} / \mathrm{ml}$; green $=\mathrm{LC3B}$, blue $=\mathrm{HOECHST})$. (B) Densitometric analysis and representative patterns of expression of LC3B-I and LC3B-II in C2C12 myotubes exposed to $5 \mathrm{ng} / \mathrm{ml}$ TNF $\alpha$. Significance of the differences: ${ }^{*} p<0.05$ vs $C,{ }^{*} p<0.01$ vs $C, \$ p<0.05$ vs TNF $\alpha$. 
1 Figure S5. Densitometric analysis and representative patterns of expression of LC3B-I and LC3B-II

2 in the muscle of $\mathrm{C}$ and TNF $\alpha$-treated mice, in the presence or in the absence of colchicine

3 administration (see Materials and methods). Significance of the differences vs $\mathrm{C}:{ }^{*} \mathrm{p}<0.05$,

$4 \quad * * \mathrm{p}<0.01$

5 Figure S6. (A)LC3B immunostaining in C2C12 myotubes (2 day differentiation) untreated or

6 treated for $48 \mathrm{~h}$ with TNFa $(100 \mathrm{ng} / \mathrm{ml})$, in the presence or in the absence of IGF1 (50 ng/ml) or

7 anti-IGF1 antibody (a-IGF1 = 2ug/ml). (B) Densitometric analysis and representative patterns of

8 expression of LC3B and phospho-Akt. Data (mean $\pm S D ; n=3$ ) are expressed as percentages of $C$.

9 Significance of the differences vs $\mathrm{C}:{ }^{*} \mathrm{p}<0.05,{ }^{*} \mathrm{p}<0.01$. 
1. Spiro A, Baldwin C, Patterson A, Thomas J, Andreyev HJ: The views and practice of oncologists towards nutritional support in patients receiving chemotherapy, $\mathrm{Br} J$ Cancer 2006, 95:431-434

2. Costelli P, Garcia-Martinez C, Llovera M, Carbo N, Lopez-Soriano FJ, Agell N, Tessitore L, Baccino FM, Argiles JM: Muscle protein waste in tumor-bearing rats is effectively antagonized by a beta 2adrenergic agonist (clenbuterol). Role of the ATP-ubiquitin-dependent proteolytic pathway, J Clin Invest 1995, 95:2367-2372

3. Bossola M, Muscaritoli M, Costelli P, Bellantone R, Pacelli F, Busquets S, Argiles J, Lopez-Soriano FJ, Civello IM, Baccino FM, Rossi Fanelli F, Doglietto GB: Increased muscle ubiquitin mRNA levels in gastric cancer patients, Am J Physiol Regul Integr Comp Physiol 2001, 280:R1518-1523

4. Scott SV, Klionsky DJ: Delivery of proteins and organelles to the vacuole from the cytoplasm, Curr Opin Cell Biol 1998, 10:523-529

5. Petiot A, Pattingre S, Arico S, Meley D, Codogno P: Diversity of signaling controls of macroautophagy in mammalian cells, Cell Struct Funct 2002, 27:431-441

6. Waterlow JC: Whole-body protein turnover in humans--past, present, and future, Annu Rev Nutr 1995, 15:57-92

7. Mizushima N, Yamamoto A, Matsui M, Yoshimori T, Ohsumi Y: In vivo analysis of autophagy in response to nutrient starvation using transgenic mice expressing a fluorescent autophagosome marker, Mol Biol Cell 2004, 15:1101-1111

8. Paul PK, Gupta SK, Bhatnagar S, Panguluri SK, Darnay BG, Choi Y, Kumar A: Targeted ablation of TRAF6 inhibits skeletal muscle wasting in mice, J Cell Biol 191:1395-1411

9. Bechet D, Tassa A, Taillandier D, Combaret L, Attaix D: Lysosomal proteolysis in skeletal muscle, Int J Biochem Cell Biol 2005, 37:2098-2114

10. Zhao J, Brault JJ, Schild A, Cao P, Sandri M, Schiaffino S, Lecker SH, Goldberg AL: FoxO3 coordinately activates protein degradation by the autophagic/lysosomal and proteasomal pathways in atrophying muscle cells, Cell Metab 2007, 6:472-483

11. Mammucari C, Milan G, Romanello V, Masiero E, Rudolf R, Del Piccolo P, Burden SJ, Di Lisi R, Sandri C, Zhao J, Goldberg AL, Schiaffino S, Sandri M: FoxO3 controls autophagy in skeletal muscle in vivo, Cell Metab 2007, 6:458-471

12. Baracos VE, DeVivo C, Hoyle DH, Goldberg AL: Activation of the ATP-ubiquitin-proteasome pathway in skeletal muscle of cachectic rats bearing a hepatoma, Am J Physiol 1995, 268:E996-1006

13. Tessitore L, Costelli P, Bonetti G, Baccino FM: Cancer cachexia, malnutrition, and tissue protein turnover in experimental animals, Arch Biochem Biophys 1993, 306:52-58

14. Tessitore L, Costelli P, Baccino FM: Pharmacological interference with tissue hypercatabolism in tumour-bearing rats, Biochem J 1994, 299 ( Pt 1):71-78

15. Deval C, Mordier S, Obled C, Bechet D, Combaret L, Attaix D, Ferrara M: Identification of cathepsin L as a differentially expressed message associated with skeletal muscle wasting, Biochem J 2001, 360:143150

16. Jagoe RT, Redfern CP, Roberts RG, Gibson GJ, Goodship TH: Skeletal muscle mRNA levels for cathepsin $\mathrm{B}$, but not components of the ubiquitin-proteasome pathway, are increased in patients with lung cancer referred for thoracotomy, Clin Sci (Lond) 2002, 102:353-361

17. Asp ML, Tian M, Wendel AA, Belury MA: Evidence for the contribution of insulin resistance to the development of cachexia in tumor-bearing mice, Int J Cancer 126:756-763

18. Lokireddy S, Wijesoma IW, Bonala S, Wei M, Sze SK, McFarlane C, Kambadur R, Sharma M:

Myostatin is a novel tumoral factor that induces cancer cachexia, Biochem J 446:23-36

19. Cosper PF, Leinwand LA: Cancer causes cardiac atrophy and autophagy in a sexually dimorphic manner, Cancer Res 71:1710-1720 
20. Doyle A, Zhang G, Abdel Fattah EA, Eissa NT, Li YP: Toll-like receptor 4 mediates lipopolysaccharideinduced muscle catabolism via coordinate activation of ubiquitin-proteasome and autophagy-lysosome pathways, FASEB J 25:99-110

21. Hasselgren PO: Glucocorticoids and muscle catabolism, Curr Opin Clin Nutr Metab Care 1999, 2:201-205

22. Schakman O, Gilson H, de Coninck V, Lause P, Verniers J, Havaux X, Ketelslegers JM, Thissen JP: Insulin-like growth factor-I gene transfer by electroporation prevents skeletal muscle atrophy in glucocorticoid-treated rats, Endocrinology 2005, 146:1789-1797

23. Schakman O, Gilson $\mathrm{H}$, Kalista S, Thissen JP: Mechanisms of muscle atrophy induced by glucocorticoids, Horm Res 2009, 72 Suppl 1:36-41

24. Yamamoto D, Maki T, Herningtyas EH, Ikeshita N, Shibahara $H$, Sugiyama $Y$, Nakanishi S, lida $K$, Iguchi G, Takahashi Y, Kaji H, Chihara K, Okimura Y: Branched-chain amino acids protect against dexamethasone-induced soleus muscle atrophy in rats, Muscle Nerve 41:819-827

25. Schakman O, Dehoux M, Bouchuari S, Delaere S, Lause P, Decroly N, Shoelson SE, Thissen JP: Role of IGF-I and the TNFalpha/NF-kappaB pathway in the induction of muscle atrogenes by acute inflammation, Am J Physiol Endocrinol Metab 303:E729-739

26. Wohlgemuth SE, Seo AY, Marzetti E, Lees HA, Leeuwenburgh C: Skeletal muscle autophagy and apoptosis during aging: effects of calorie restriction and life-long exercise, Exp Gerontol 45:138-148 27. Fry CS, Drummond MJ, Glynn EL, Dickinson JM, Gundermann DM, Timmerman KL, Walker DK, Volpi E, Rasmussen BB: Skeletal Muscle Autophagy and Protein Breakdown Following Resistance Exercise are Similar in Younger and Older Adults, J Gerontol A Biol Sci Med Sci

28. Langen RC, Van Der Velden JL, Schols AM, Kelders MC, Wouters EF, Janssen-Heininger YM: Tumor necrosis factor-alpha inhibits myogenic differentiation through MyoD protein destabilization, FASEB J 2004, 18:227-237

29. Langen RC, Schols AM, Kelders MC, van der Velden JL, Wouters EF, Janssen-Heininger YM: Muscle wasting and impaired muscle regeneration in a murine model of chronic pulmonary inflammation, Am J Respir Cell Mol Biol 2006, 35:689-696

30. Klionsky DJ, Abeliovich H, Agostinis P, Agrawal DK, Aliev G, Askew DS, Baba M, Baehrecke EH, Bahr BA, Ballabio A, Bamber BA, Bassham DC, Bergamini E, Bi X, Biard-Piechaczyk M, Blum JS, Bredesen DE, Brodsky JL, Brumell JH, Brunk UT, Bursch W, Camougrand N, Cebollero E, Cecconi F, Chen Y, Chin LS, Choi A, Chu CT, Chung J, Clarke PG, Clark RS, Clarke SG, Clave C, Cleveland JL, Codogno P, Colombo MI, CotoMontes A, Cregg JM, Cuervo AM, Debnath J, Demarchi F, Dennis PB, Dennis PA, Deretic V, Devenish RJ, Di Sano F, Dice JF, Difiglia M, Dinesh-Kumar S, Distelhorst CW, Djavaheri-Mergny M, Dorsey FC, Droge W, Dron M, Dunn WA, Jr., Duszenko M, Eissa NT, Elazar Z, Esclatine A, Eskelinen EL, Fesus L, Finley KD, Fuentes JM, Fueyo J, Fujisaki K, Galliot B, Gao FB, Gewirtz DA, Gibson SB, Gohla A, Goldberg AL, Gonzalez R, GonzalezEstevez C, Gorski S, Gottlieb RA, Haussinger D, He YW, Heidenreich K, Hill JA, Hoyer-Hansen M, Hu X, Huang WP, Iwasaki A, Jaattela $M$, Jackson WT, Jiang $X$, Jin $S$, Johansen $T$, Jung JU, Kadowaki $M$, Kang C, Kelekar A, Kessel DH, Kiel JA, Kim HP, Kimchi A, Kinsella TJ, Kiselyov K, Kitamoto K, Knecht E, Komatsu M, Kominami E, Kondo S, Kovacs AL, Kroemer G, Kuan CY, Kumar R, Kundu M, Landry J, Laporte M, Le W, Lei HY, Lenardo MJ, Levine B, Lieberman A, Lim KL, Lin FC, Liou W, Liu LF, Lopez-Berestein G, Lopez-Otin C, Lu B, Macleod KF, Malorni W, Martinet W, Matsuoka K, Mautner J, Meijer AJ, Melendez A, Michels P, Miotto G, Mistiaen WP, Mizushima N, Mograbi B, Monastyrska I, Moore MN, Moreira PI, Moriyasu Y, Motyl T, Munz C, Murphy LO, Naqvi NI, Neufeld TP, Nishino I, Nixon RA, Noda T, Nurnberg B, Ogawa M, Oleinick NL, Olsen LJ, Ozpolat B, Paglin S, Palmer GE, Papassideri I, Parkes M, Perlmutter DH, Perry G, Piacentini M, Pinkas-Kramarski R, Prescott M, Proikas-Cezanne T, Raben N, Rami A, Reggiori F, Rohrer B, Rubinsztein DC, Ryan KM, Sadoshima J, Sakagami H, Sakai Y, Sandri M, Sasakawa C, Sass M, Schneider C, Seglen PO, Seleverstov O, Settleman J, Shacka JJ, Shapiro IM, Sibirny A, Silva-Zacarin EC, Simon HU, Simone C, Simonsen A, Smith MA, SpanelBorowski K, Srinivas V, Steeves M, Stenmark H, Stromhaug PE, Subauste CS, Sugimoto S, Sulzer D, Suzuki T, Swanson MS, Tabas I, Takeshita F, Talbot NJ, Talloczy Z, Tanaka K, Tanida I, Taylor GS, Taylor JP, Terman A, Tettamanti G, Thompson CB, Thumm M, Tolkovsky AM, Tooze SA, Truant R, Tumanovska LV, Uchiyama Y, 
Ueno T, Uzcategui NL, van der Klei I, Vaquero EC, Vellai T, Vogel MW, Wang HG, Webster P, Wiley JW, Xi Z, Xiao G, Yahalom J, Yang JM, Yap G, Yin XM, Yoshimori T, Yu L, Yue Z, Yuzaki M, Zabirnyk O, Zheng X, Zhu X, Deter RL: Guidelines for the use and interpretation of assays for monitoring autophagy in higher eukaryotes, Autophagy 2008, 4:151-175

31. Funderburk SF, Wang QJ, Yue Z: The Beclin 1-VPS34 complex--at the crossroads of autophagy and beyond, Trends Cell Biol 20:355-362

32. Bjorkoy G, Lamark T, Pankiv S, Overvatn A, Brech A, Johansen T: Monitoring autophagic degradation of p62/SQSTM1, Methods Enzymol 2009, 452:181-197

33. Ju JS, Varadhachary AS, Miller SE, Weihl CC: Quantitation of "autophagic flux" in mature skeletal muscle, Autophagy 6:929-935

34. Ren Y, Zhao J, Feng J: Parkin binds to alpha/beta tubulin and increases their ubiquitination and degradation, J Neurosci 2003, 23:3316-3324

35. Del Roso A, Vittorini S, Cavallini G, Donati A, Gori Z, Masini M, Pollera M, Bergamini E: Ageingrelated changes in the in vivo function of rat liver macroautophagy and proteolysis, Exp Gerontol 2003, 38:519-527

36. Costelli P, Bossola M, Muscaritoli M, Grieco G, Bonelli G, Bellantone R, Doglietto GB, Baccino FM, Rossi Fanelli F: Anticytokine treatment prevents the increase in the activity of ATP-ubiquitin- and $\mathrm{Ca}(2+)$ dependent proteolytic systems in the muscle of tumour-bearing rats, Cytokine 2002, 19:1-5

37. Llovera M, Carbo N, Garcia-Martinez C, Costelli P, Tessitore L, Baccino FM, Agell N, Bagby GJ, LopezSoriano FJ, Argiles JM: Anti-TNF treatment reverts increased muscle ubiquitin gene expression in tumourbearing rats, Biochem Biophys Res Commun 1996, 221:653-655

38. Dogra C, Changotra H, Wedhas N, Qin X, Wergedal JE, Kumar A: TNF-related weak inducer of apoptosis (TWEAK) is a potent skeletal muscle-wasting cytokine, FASEB J 2007, 21:1857-1869

39. Moylan JS, Smith JD, Chambers MA, McLoughlin TJ, Reid MB: TNF induction of atrogin-1/MAFbx mRNA depends on Foxo4 expression but not AKT-Foxo1/3 signaling, Am J Physiol Cell Physiol 2008, 295:C986-993

40. Rubinsztein DC, Cuervo AM, Ravikumar B, Sarkar S, Korolchuk V, Kaushik S, Klionsky DJ: In search of an "autophagomometer", Autophagy 2009, 5:585-589

41. Attaix D, Combaret L, Bechet D, Taillandier D: Role of the ubiquitin-proteasome pathway in muscle atrophy in cachexia, Curr Opin Support Palliat Care 2008, 2:262-266

42. Acharyya $S$, Guttridge DC: Cancer cachexia signaling pathways continue to emerge yet much still points to the proteasome, Clin Cancer Res 2007, 13:1356-1361

43. Khal J, Wyke SM, Russell ST, Hine AV, Tisdale MJ: Expression of the ubiquitin-proteasome pathway and muscle loss in experimental cancer cachexia, Br J Cancer 2005, 93:774-780

44. Zhang G, Jin B, Li YP: C/EBPbeta mediates tumour-induced ubiquitin ligase atrogin1/MAFbx upregulation and muscle wasting, EMBO J 30:4323-4335

45. Paul PK, Kumar A: TRAF6 coordinates the activation of autophagy and ubiquitin-proteasome systems in atrophying skeletal muscle, Autophagy 7 :

46. Zhao J, Brault JJ, Schild A, Goldberg AL: Coordinate activation of autophagy and the proteasome pathway by FoxO transcription factor, Autophagy 2008, 4:378-380

47. Johansen T, Lamark T: Selective autophagy mediated by autophagic adapter proteins, Autophagy 7:279-296

48. Zheng $\mathrm{H}$, Tang $\mathrm{M}$, Zheng $\mathrm{Q}$, Kumarapeli AR, Horak KM, Tian Z, Wang X: Doxycycline attenuates protein aggregation in cardiomyocytes and improves survival of a mouse model of cardiac proteinopathy, $J$ Am Coll Cardiol 56:1418-1426

49. Eskelinen EL, Illert AL, Tanaka Y, Schwarzmann G, Blanz J, Von Figura K, Saftig P: Role of LAMP-2 in lysosome biogenesis and autophagy, Mol Biol Cell 2002, 13:3355-3368

50. Hepple RT, Qin M, Nakamoto H, Goto S: Caloric restriction optimizes the proteasome pathway with aging in rat plantaris muscle: implications for sarcopenia, Am J Physiol Regul Integr Comp Physiol 2008, 295:R1231-1237 
1 51. Masiero E, Agatea L, Mammucari C, Blaauw B, Loro E, Komatsu M, Metzger D, Reggiani C, Schiaffino 2 S, Sandri M: Autophagy is required to maintain muscle mass, Cell Metab 2009, 10:507-515

3 52. Czaja MJ: Functions of autophagy in hepatic and pancreatic physiology and disease, 4 Gastroenterology 140:1895-1908

5 53. Martinez-Outschoorn UE, Whitaker-Menezes D, Pavlides S, Chiavarina B, Bonuccelli G, Casey T, 6 Tsirigos A, Migneco G, Witkiewicz A, Balliet R, Mercier I, Wang C, Flomenberg N, Howell A, Lin Z, Caro J, 7 Pestell RG, Sotgia F, Lisanti MP: The autophagic tumor stroma model of cancer or "battery-operated tumor 8 growth": A simple solution to the autophagy paradox, Cell Cycle 9:4297-4306

9 54. Penna F, Minero VG, Costamagna D, Bonelli G, Baccino FM, Costelli P: Anti-cytokine strategies for the treatment of cancer-related anorexia and cachexia, Expert Opin Biol Ther 10:1241-1250 Opin Support Palliat Care 2009, 3:263-268

56. Bhatnagar S, Mittal A, Gupta SK, Kumar A: TWEAK causes myotube atrophy through coordinated activation of ubiquitin-proteasome system, autophagy, and caspases, J Cell Physiol

57. Penna F, Bonetto A, Muscaritoli M, Costamagna D, Minero VG, Bonelli G, Rossi Fanelli F, Baccino FM, Costelli P: Muscle atrophy in experimental cancer cachexia: is the IGF-1 signaling pathway involved?, Int J Cancer 127:1706-1717

58. Schmidt K, von Haehling S, Doehner W, Palus S, Anker SD, Springer J: IGF-1 treatment reduces weight loss and improves outcome in a rat model of cancer cachexia, J Cachex Sarcopenia Muscle 2:105109

59. Shi J, Luo L, Eash J, Ibebunjo C, Glass DJ: The SCF-Fbxo40 complex induces IRS1 ubiquitination in skeletal muscle, limiting IGF1 signaling, Dev Cell 21:835-847 
A
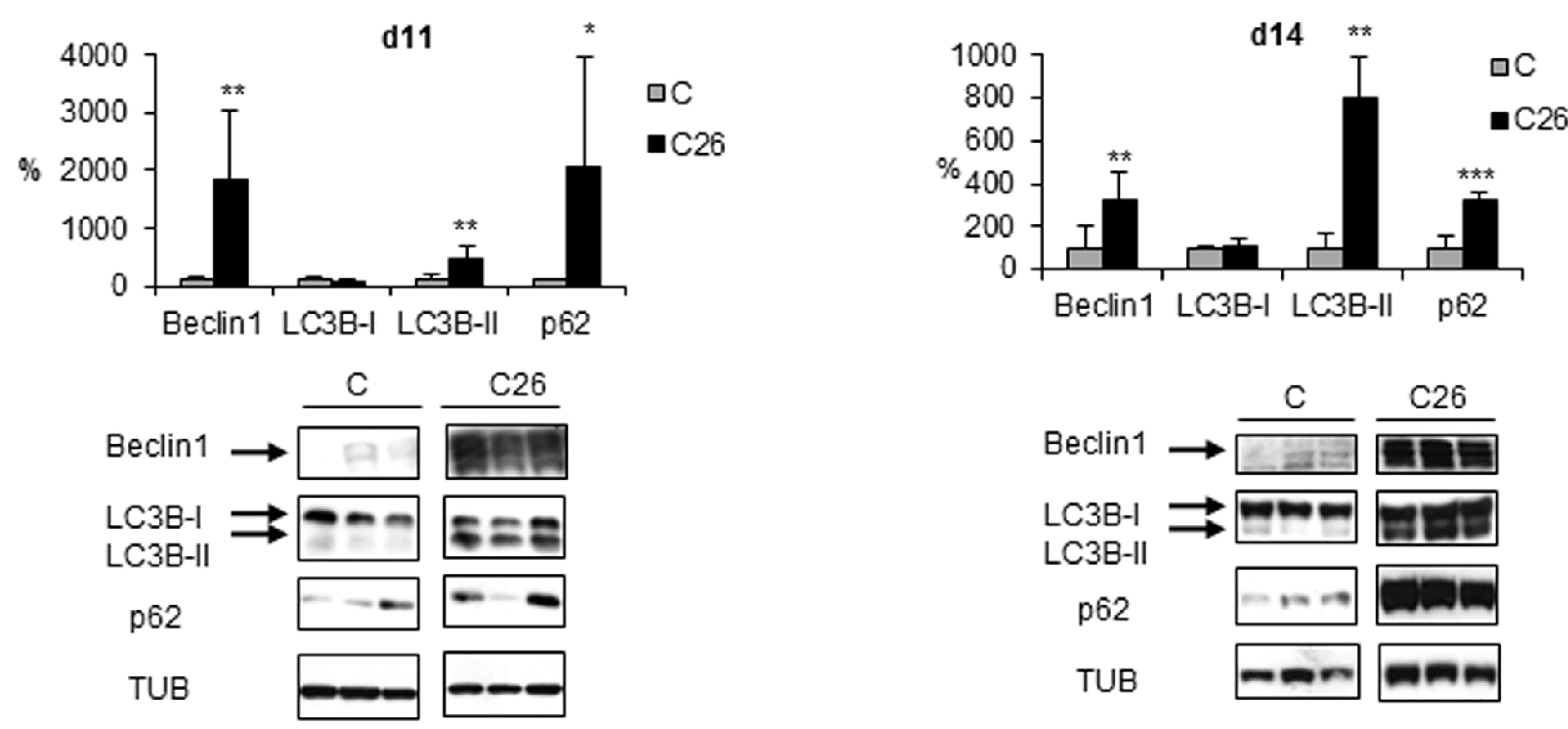

B

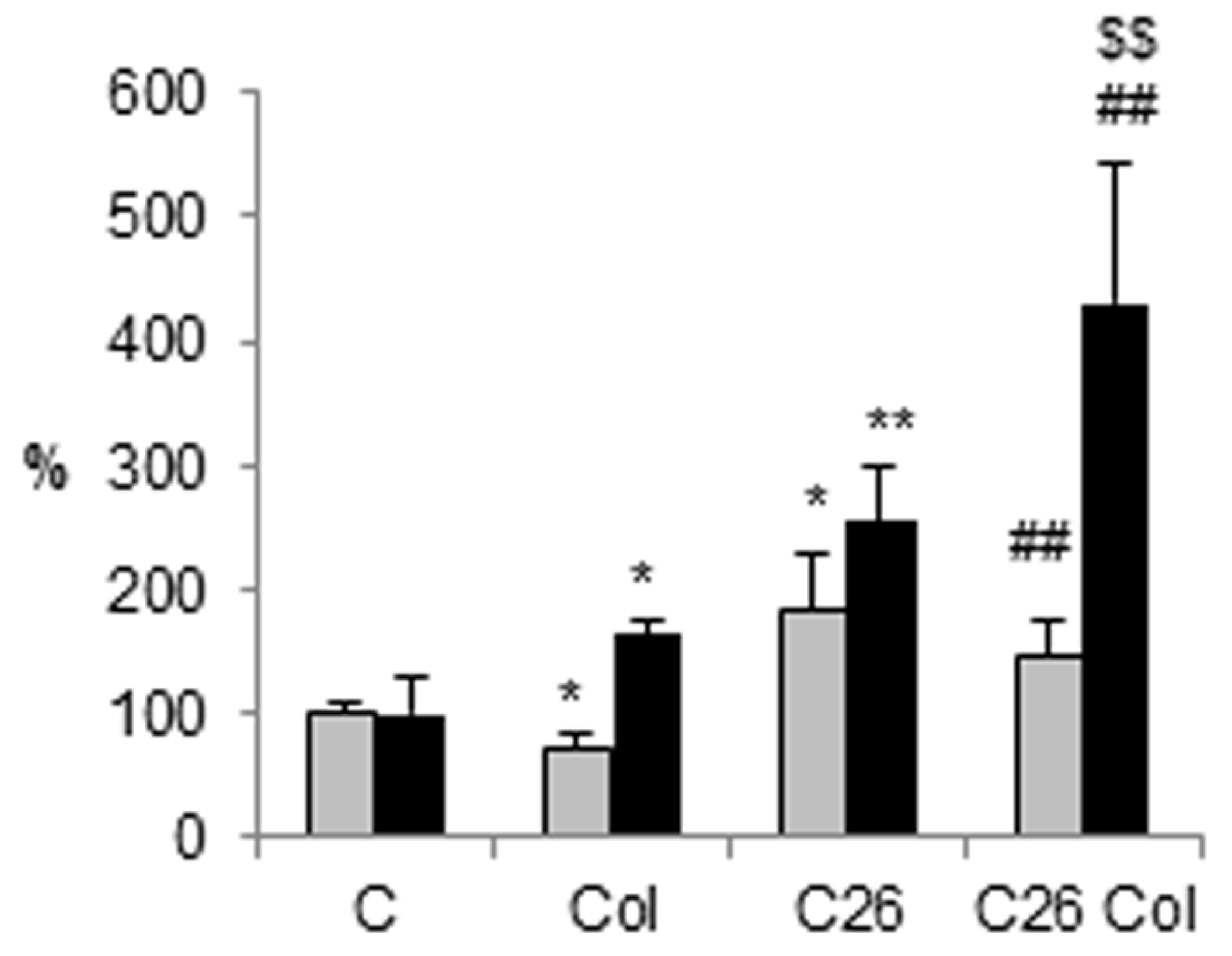

ㄴC3B-I
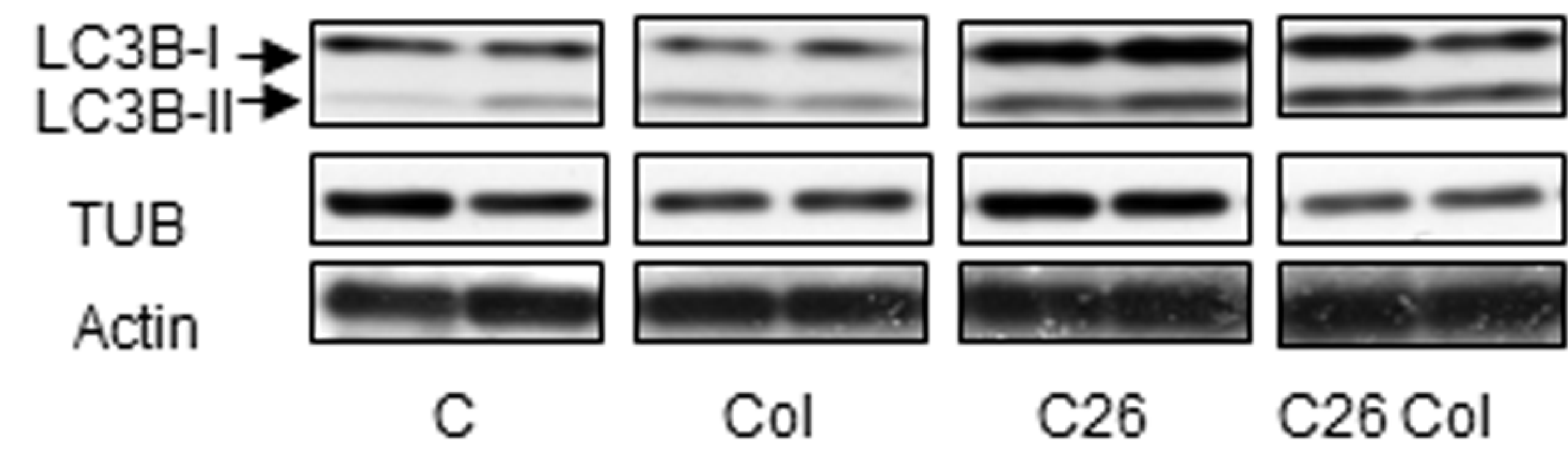

- LC3B-II

Col

C26

$26 \mathrm{Col}$ 
Figure 2

A

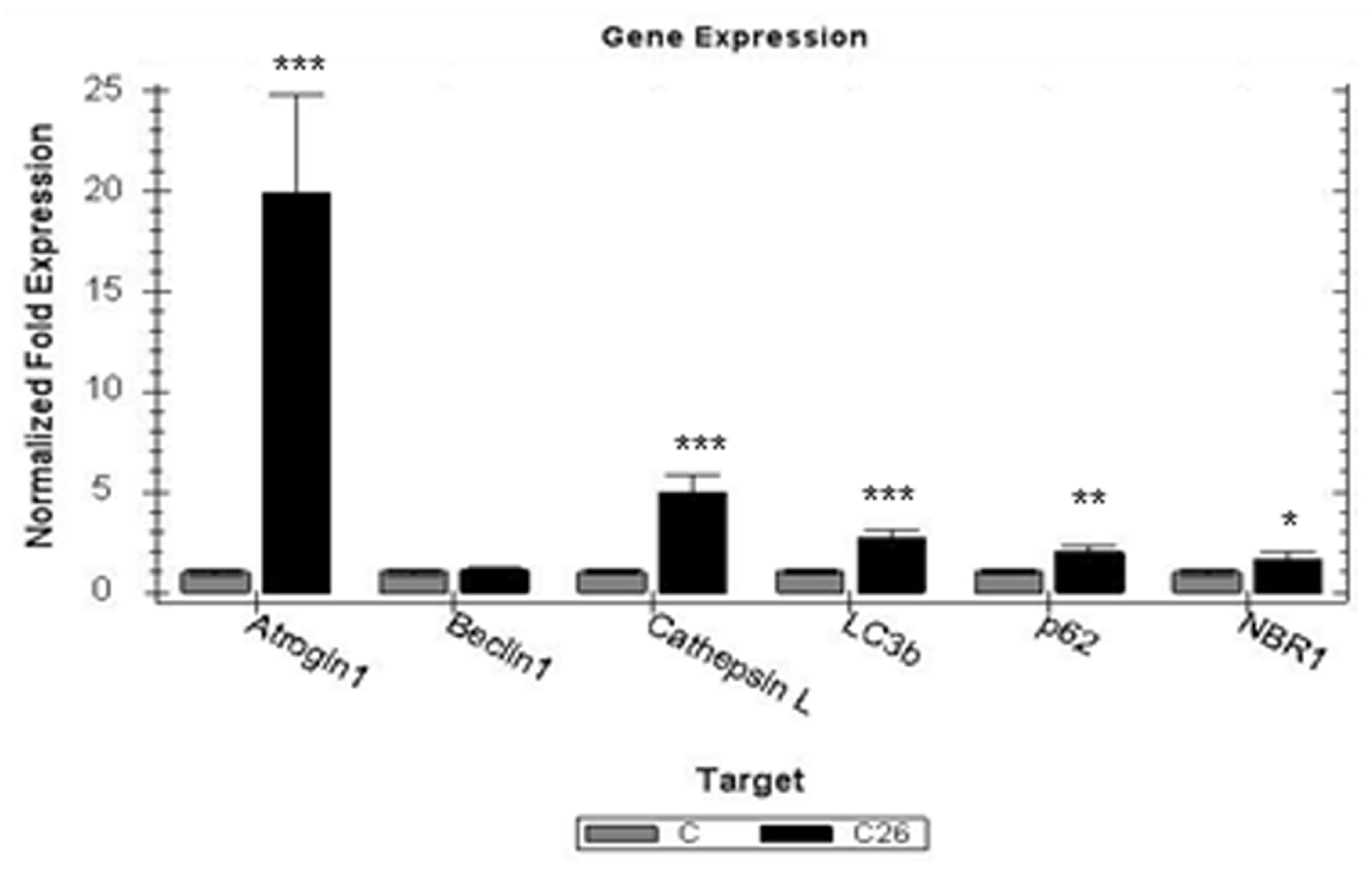

B

Cathepsin B+L activity - d11

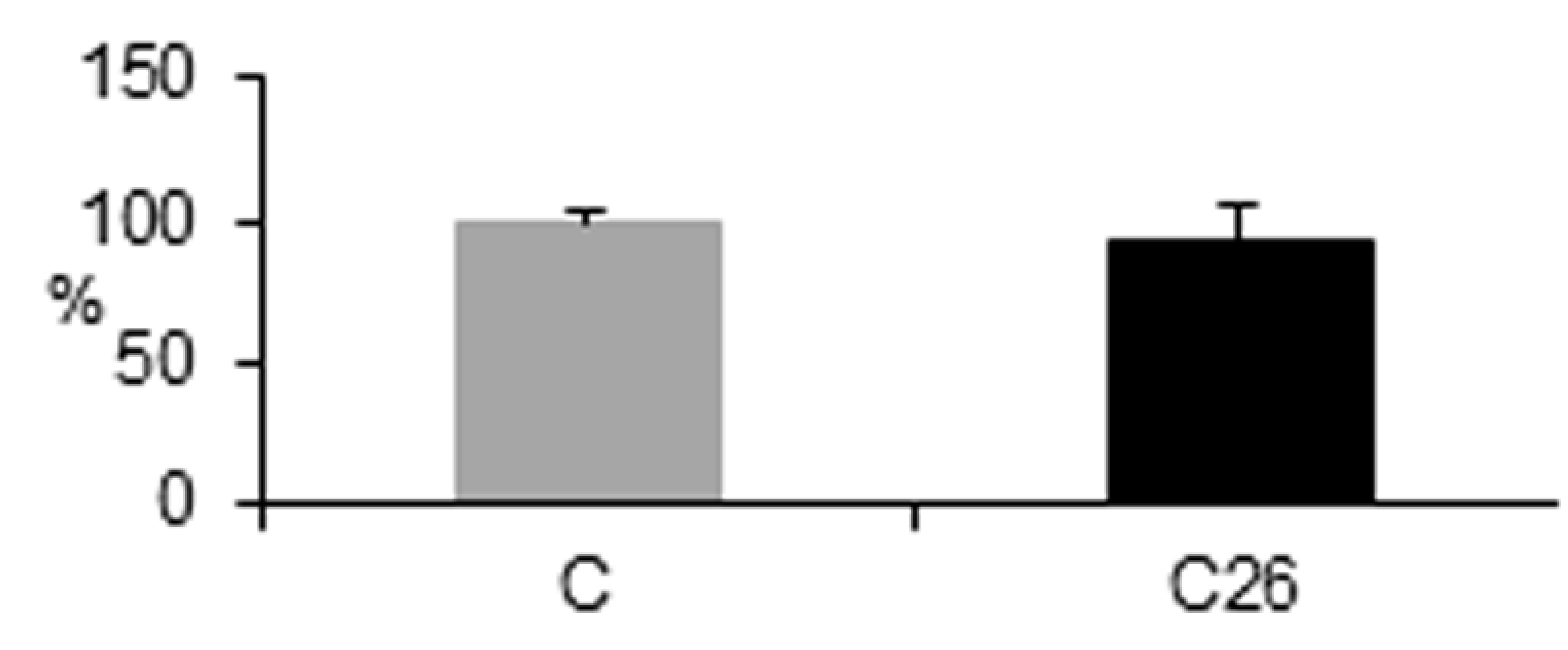

Cathepsin B+L activity - d14

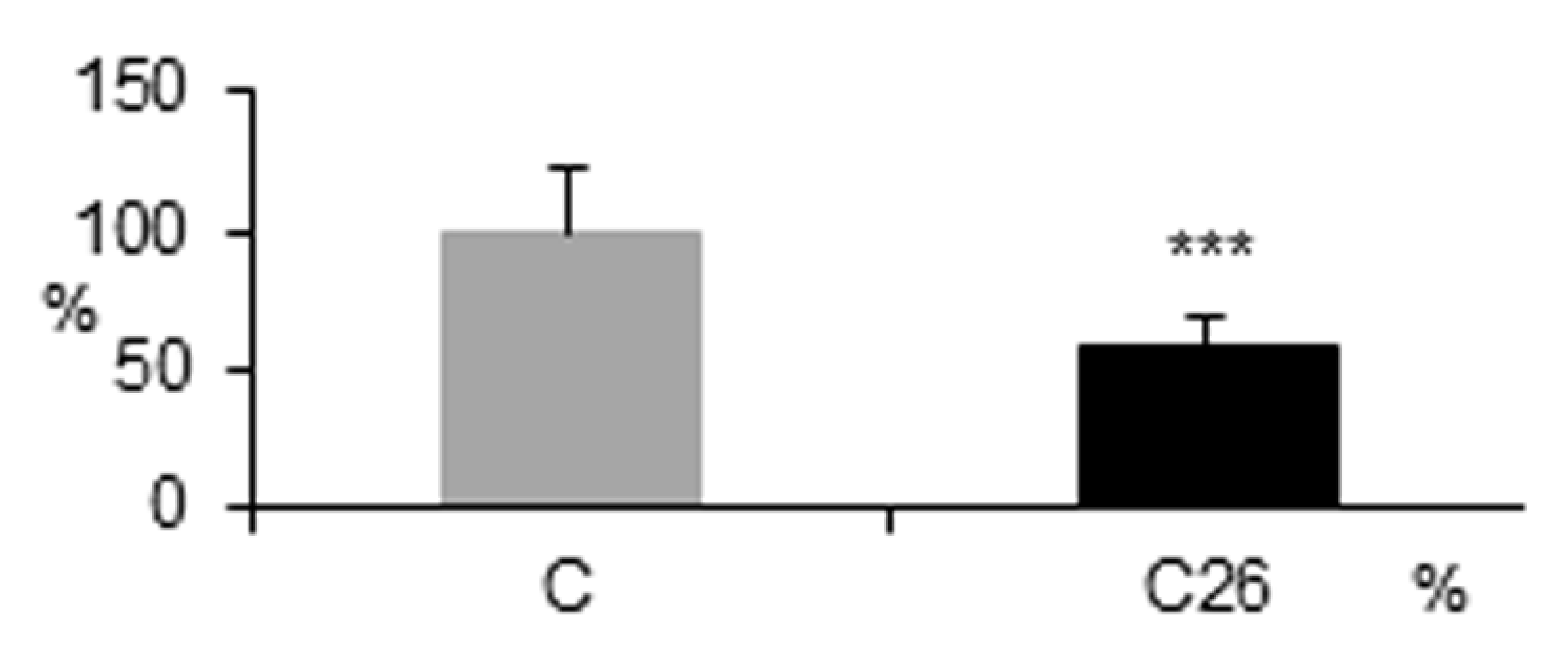


Figure 3

A

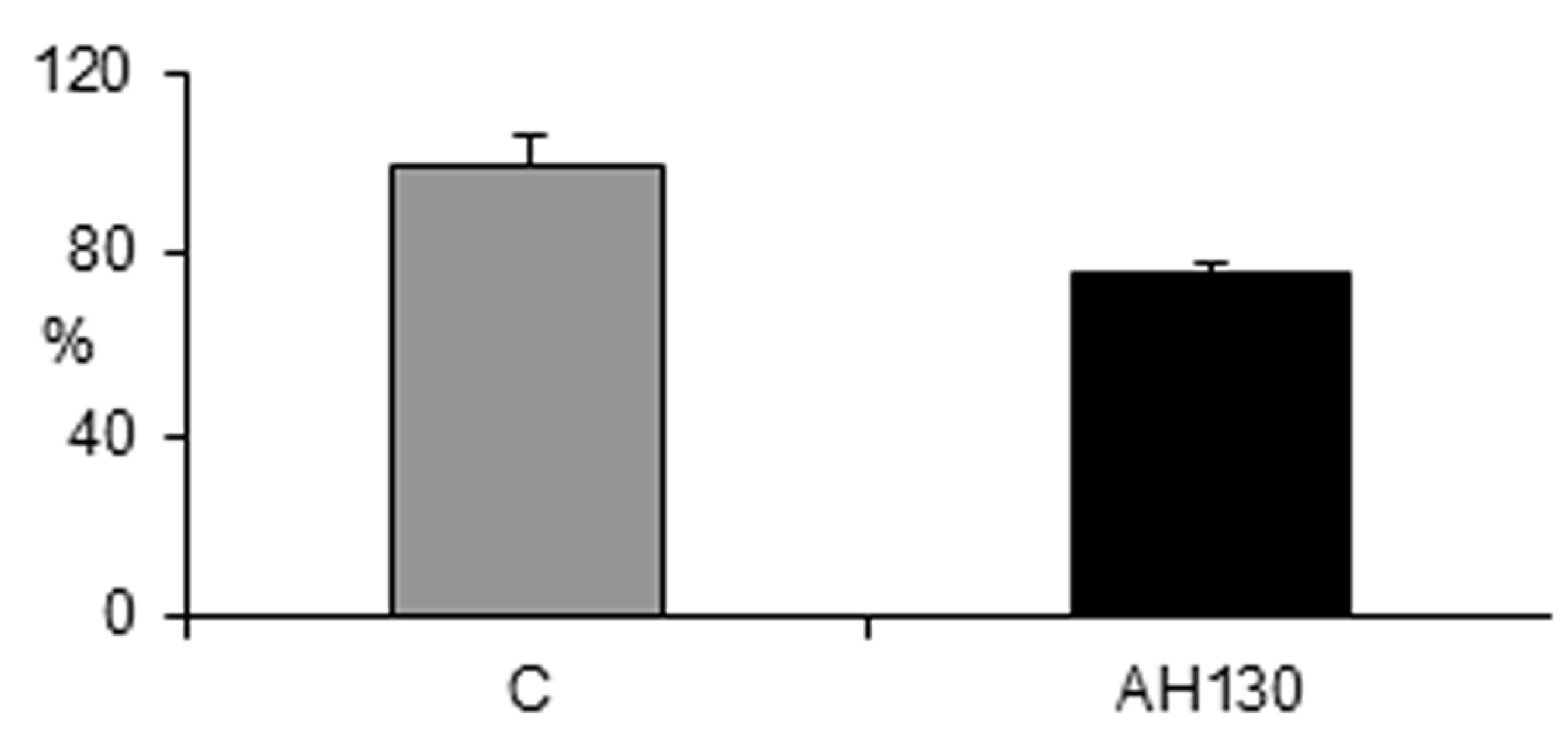

C

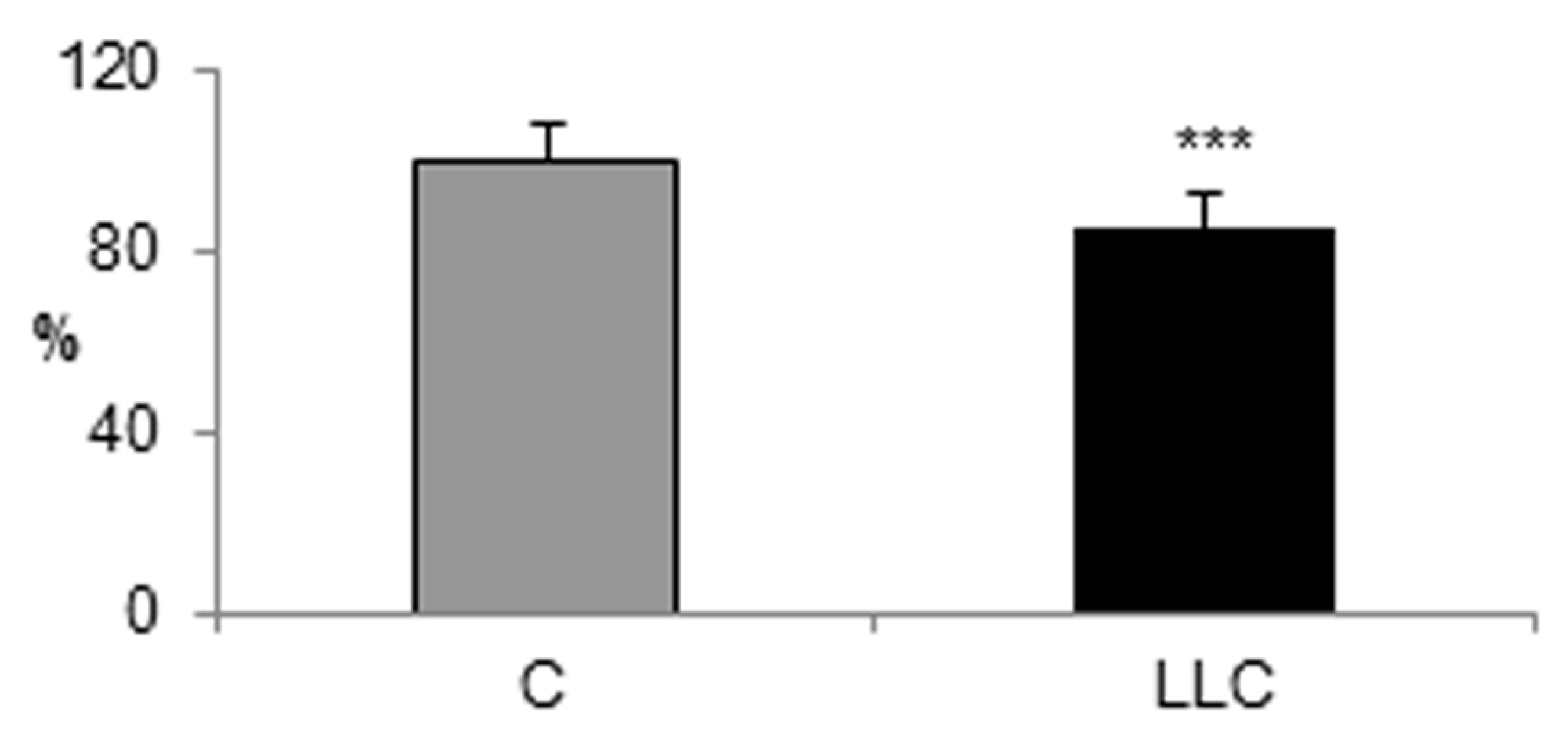

B
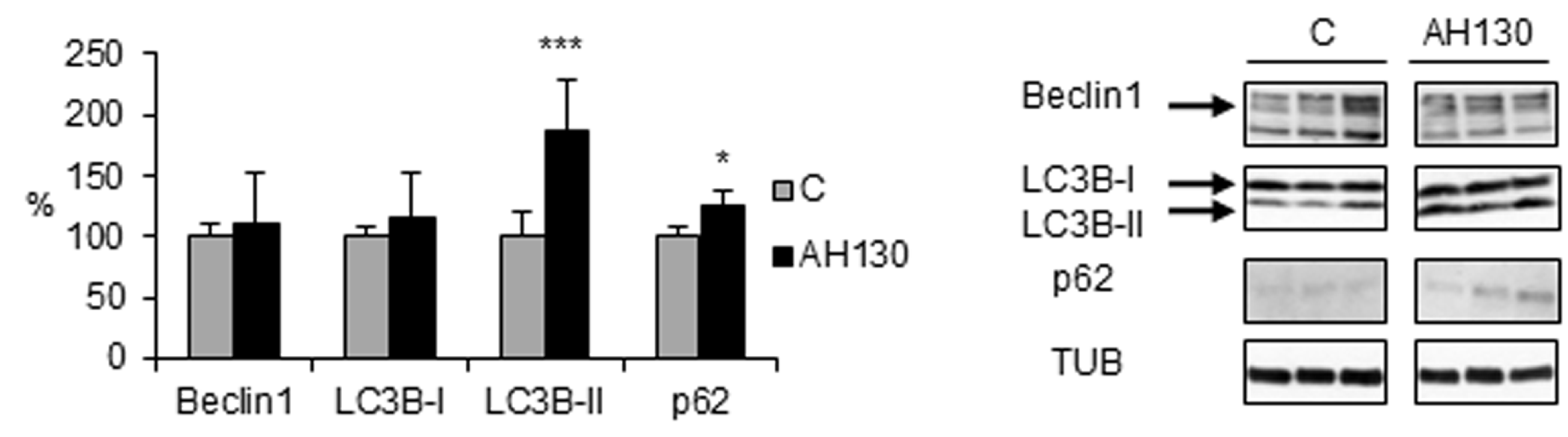

D

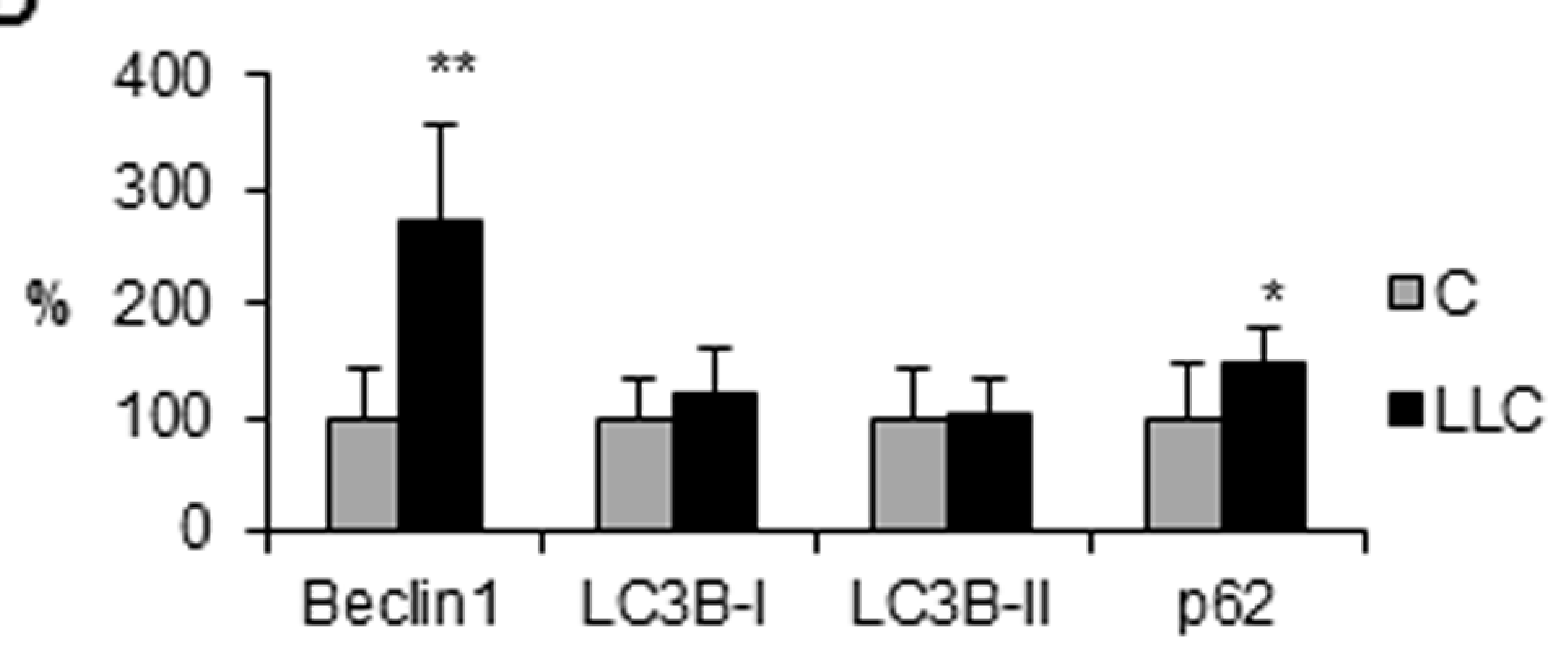

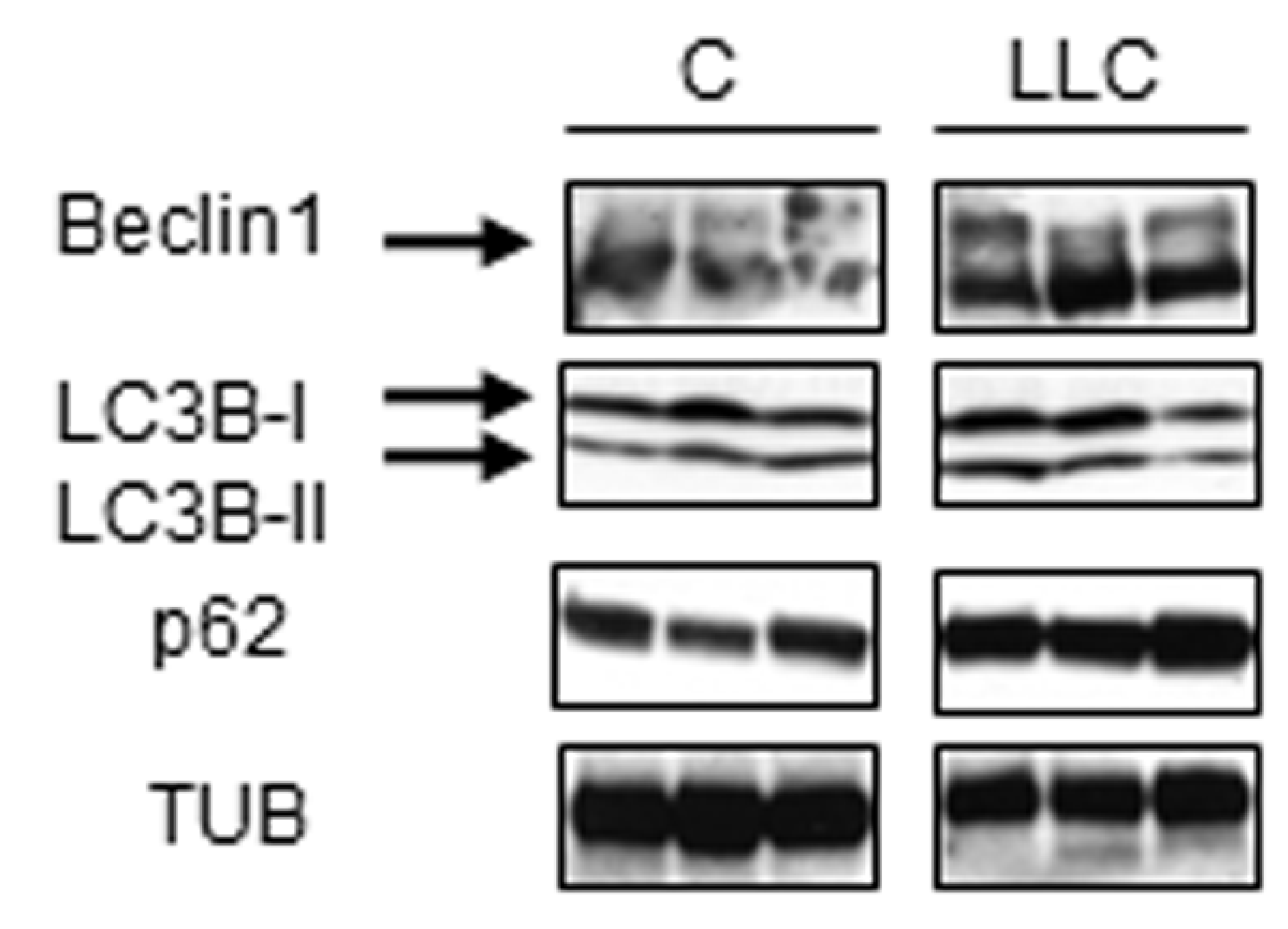


Figure 4

A
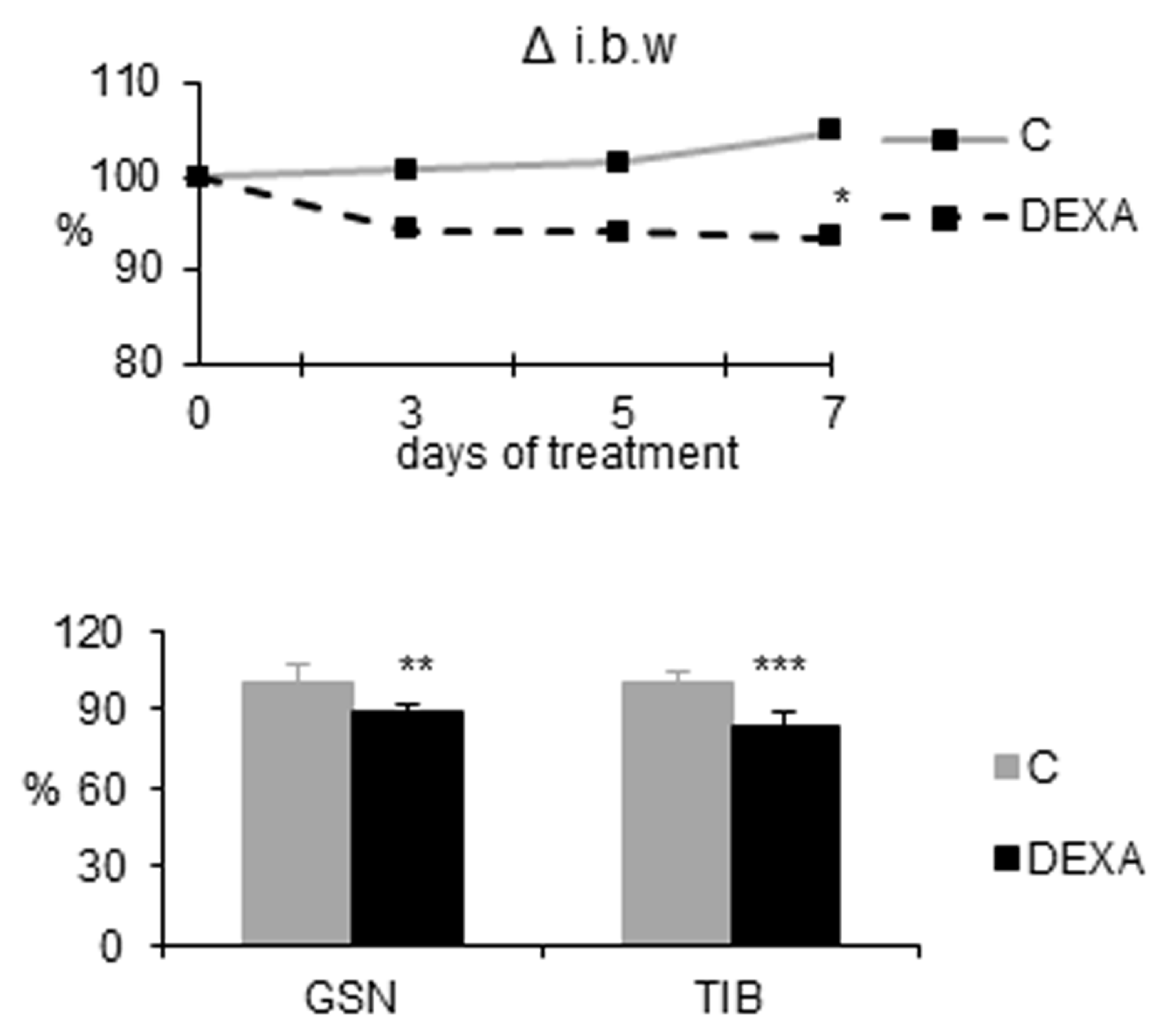

C

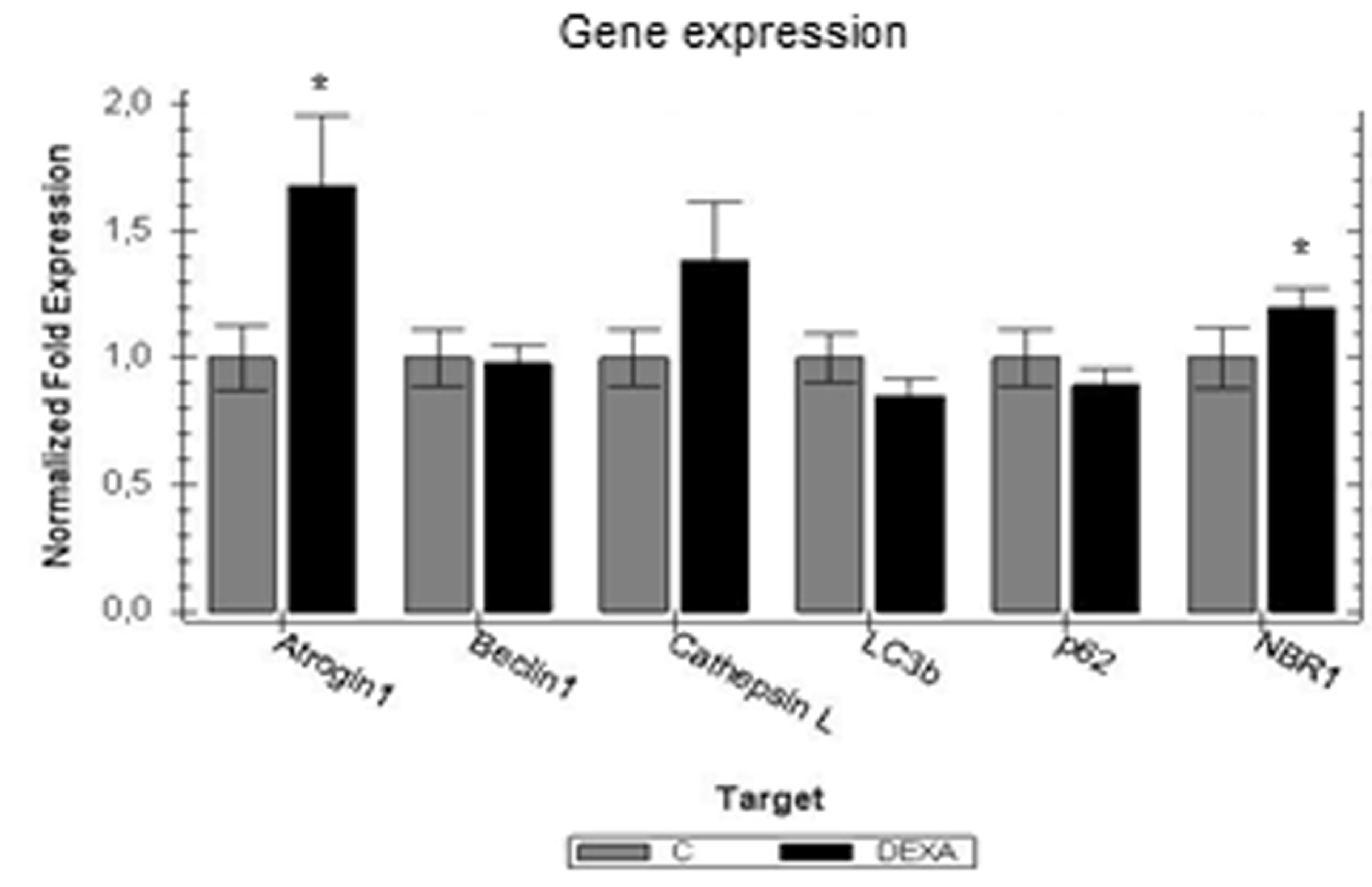

B
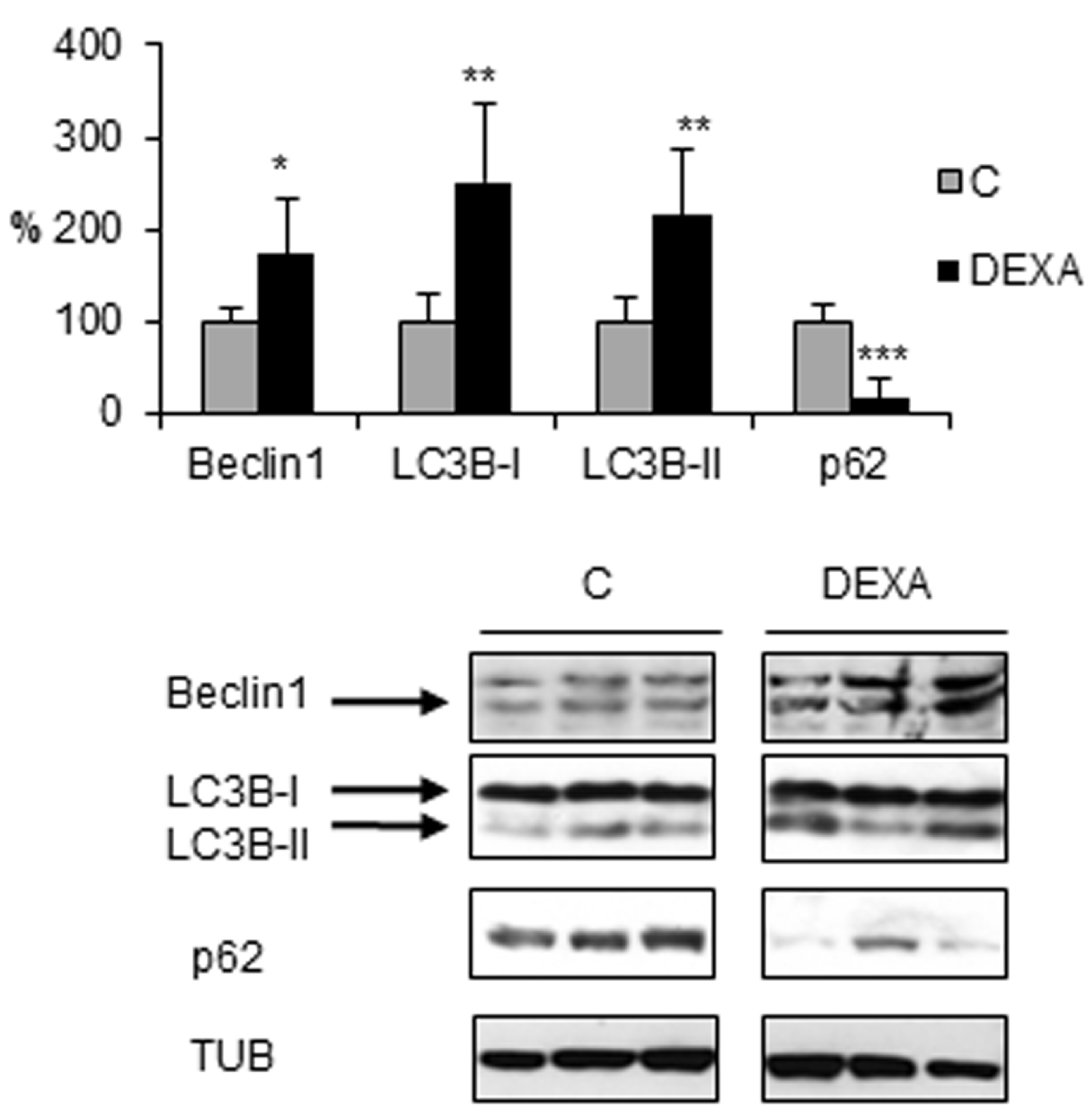

D

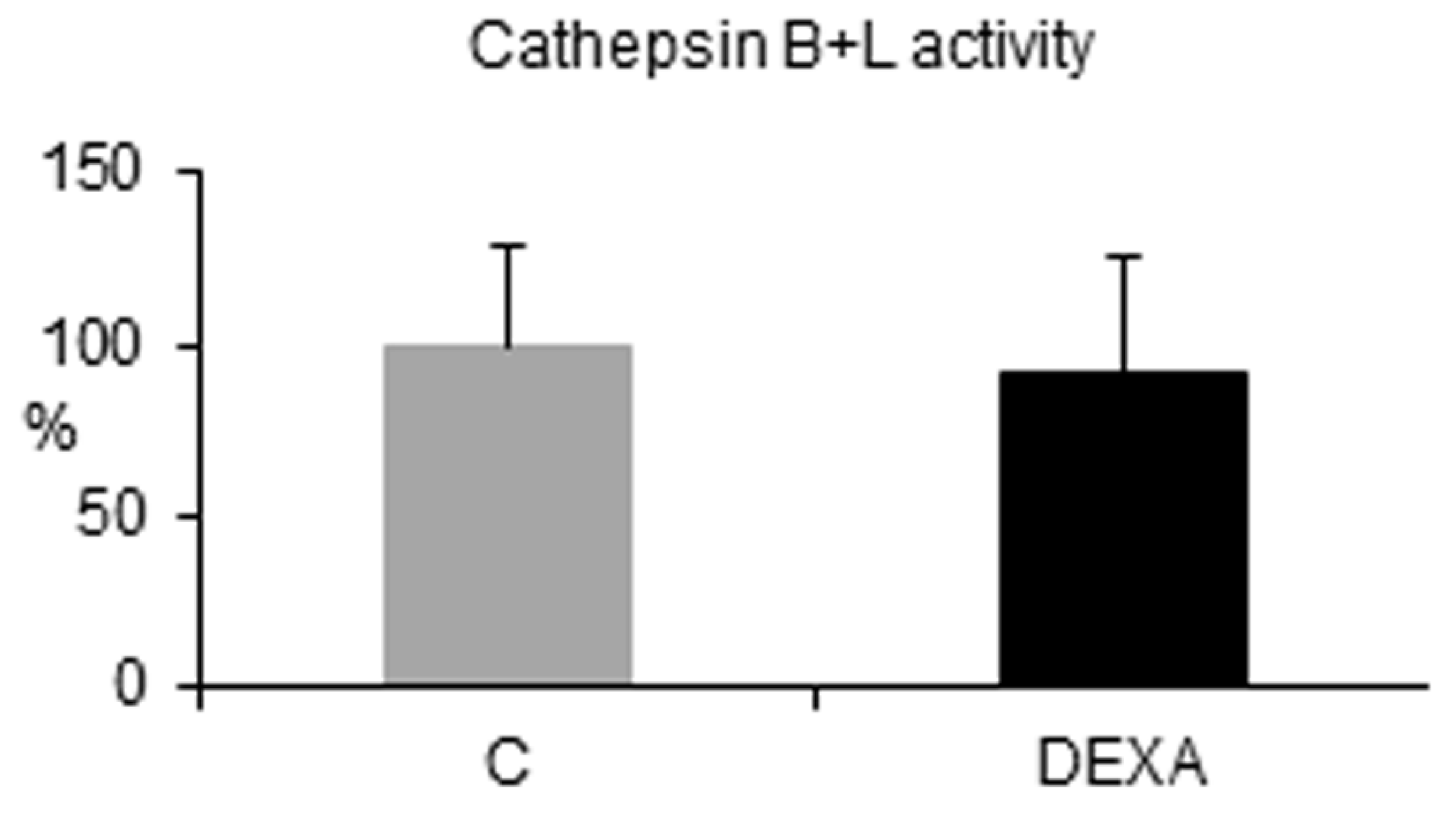


Figure 5

A

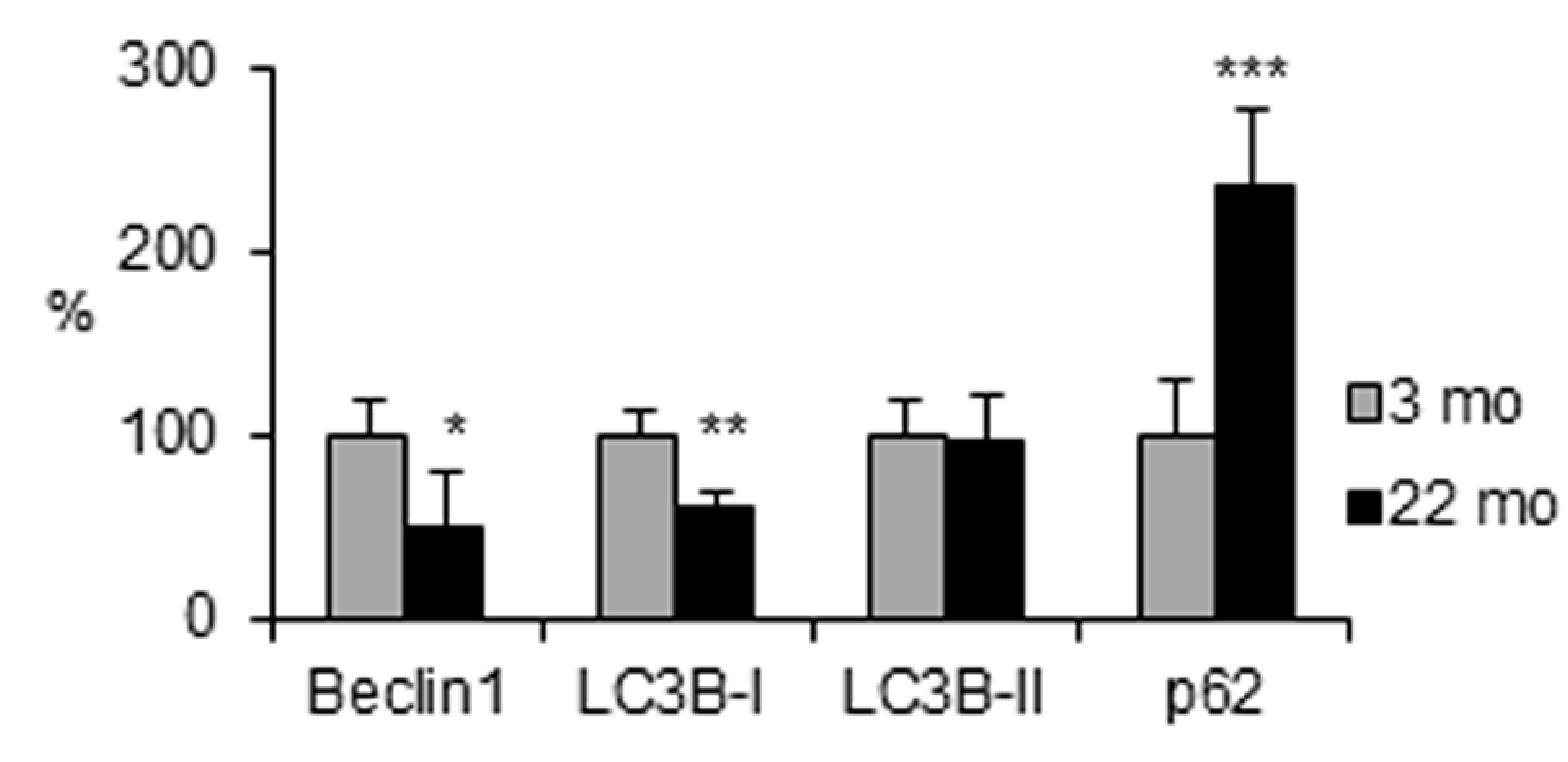

B

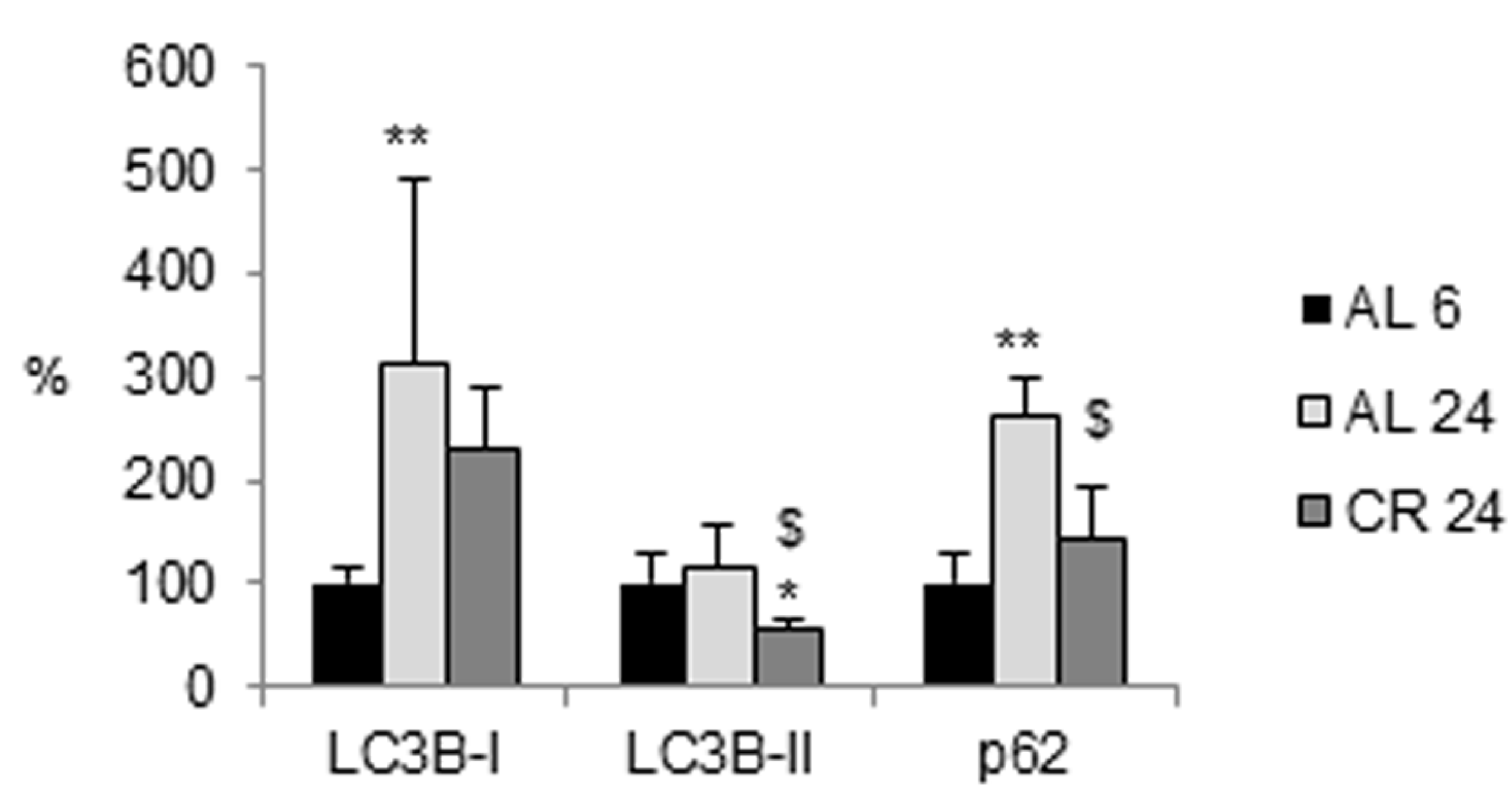


Figure 6
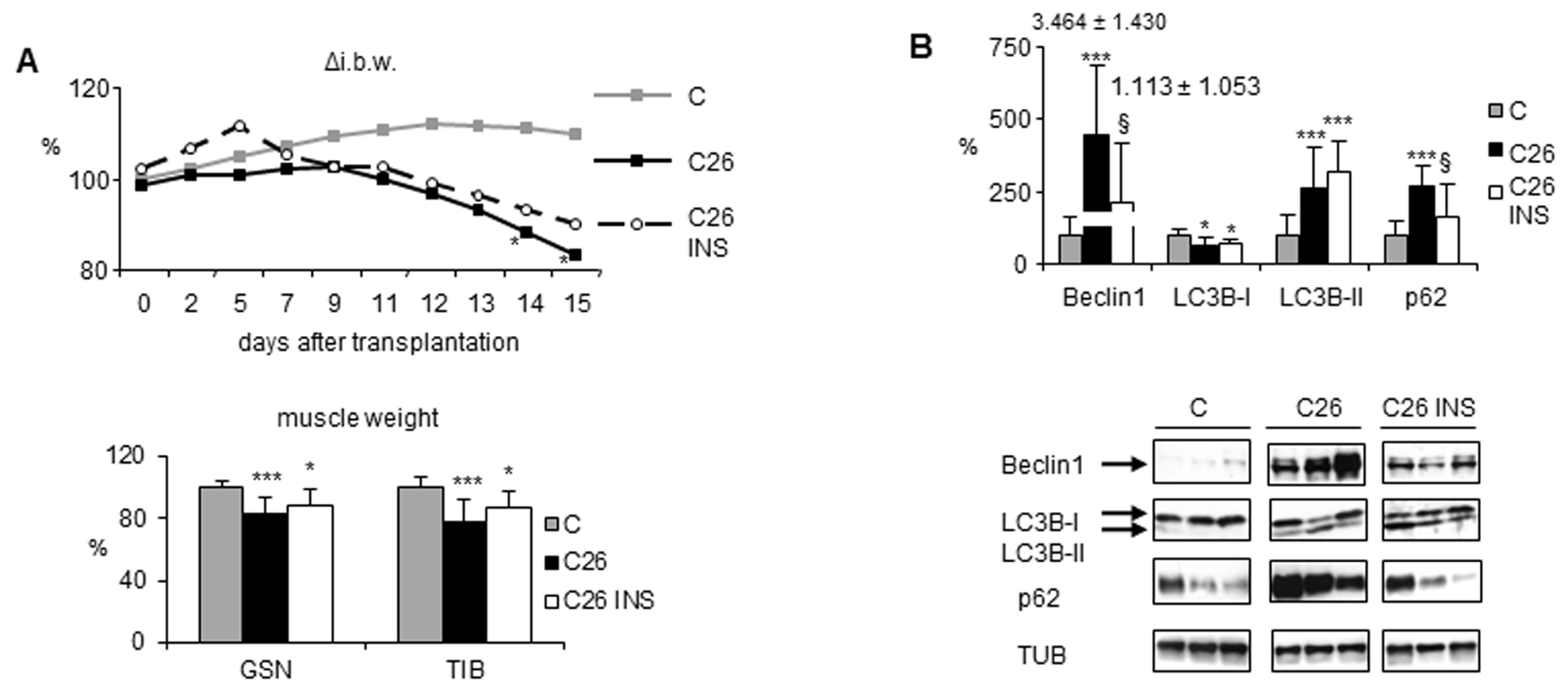

C

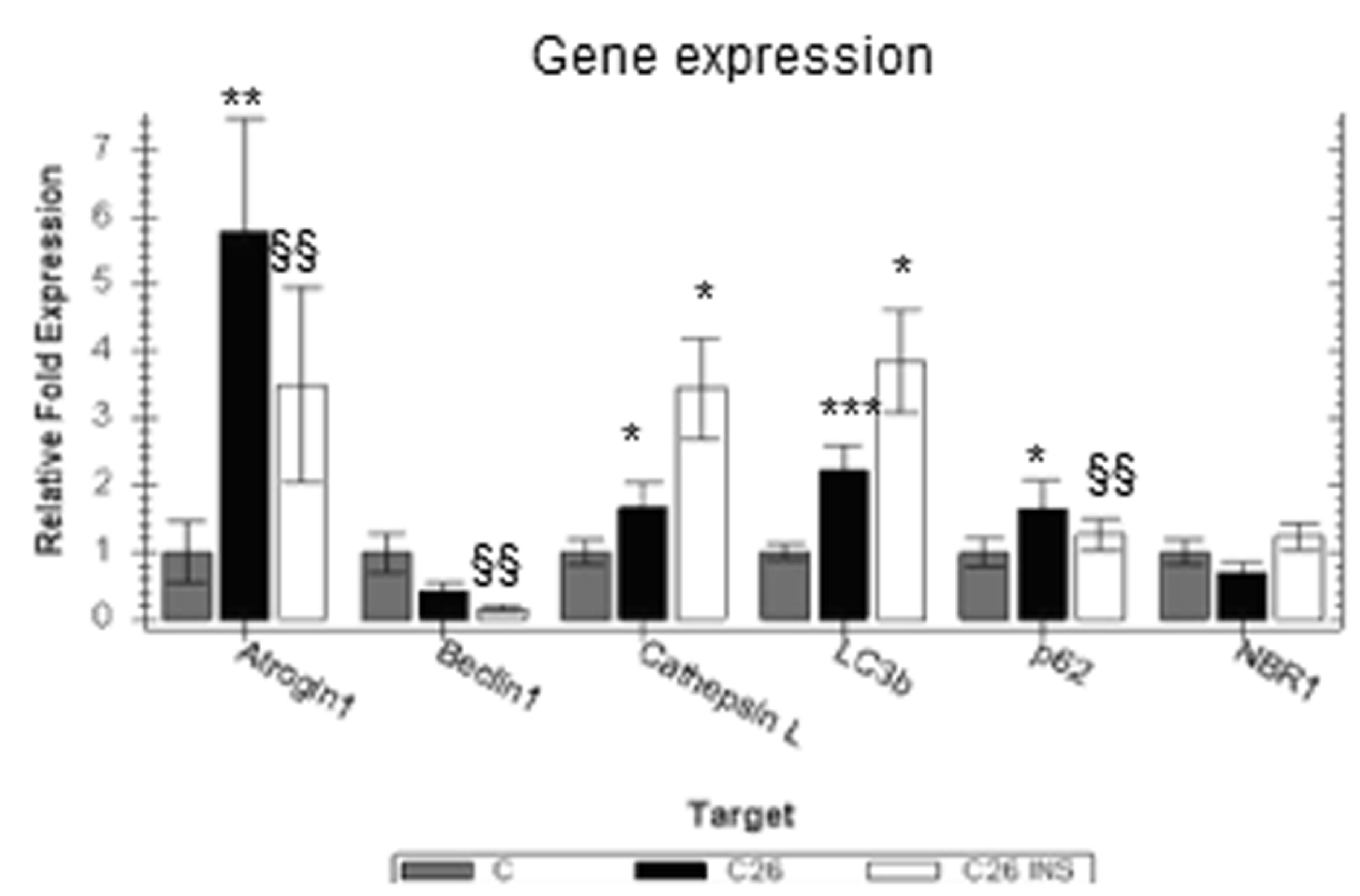


Figure 7

A

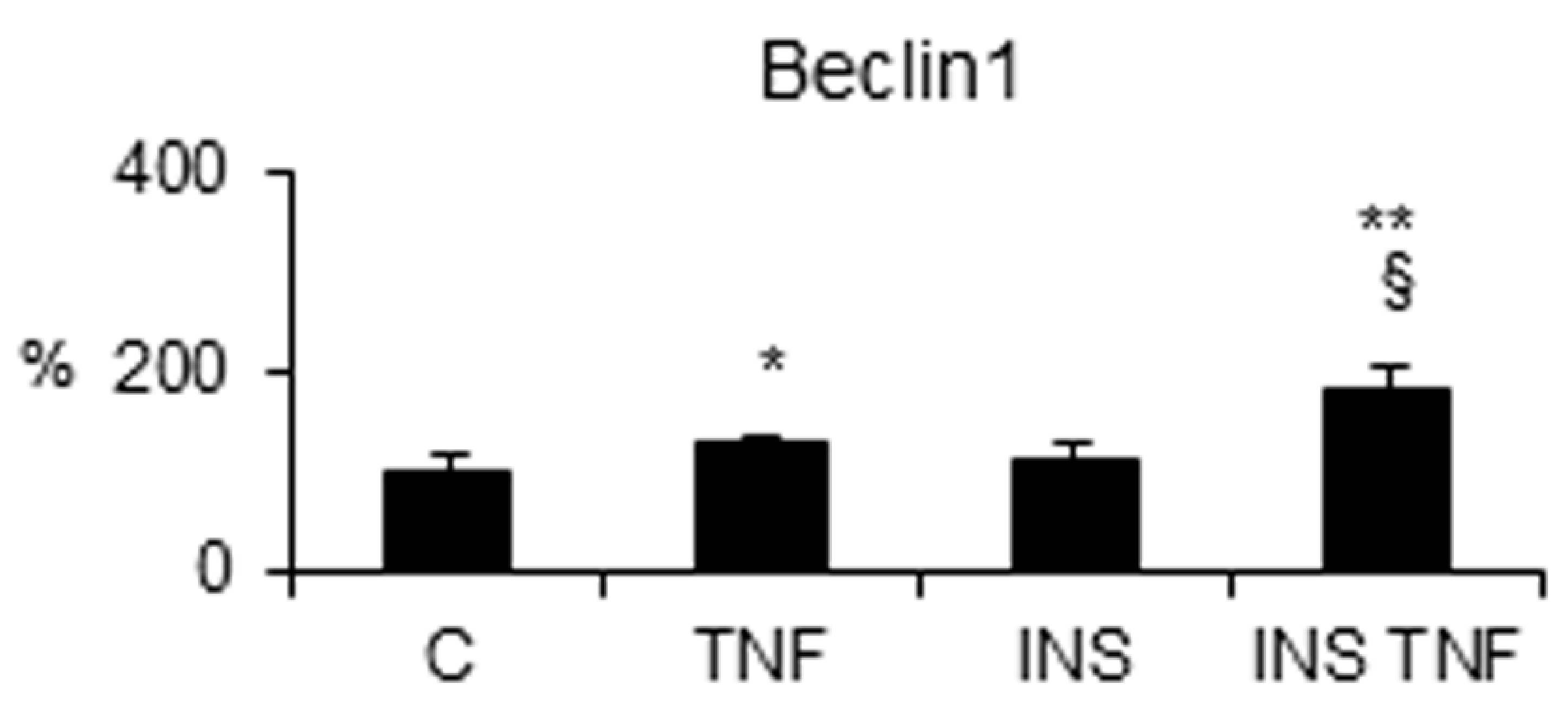

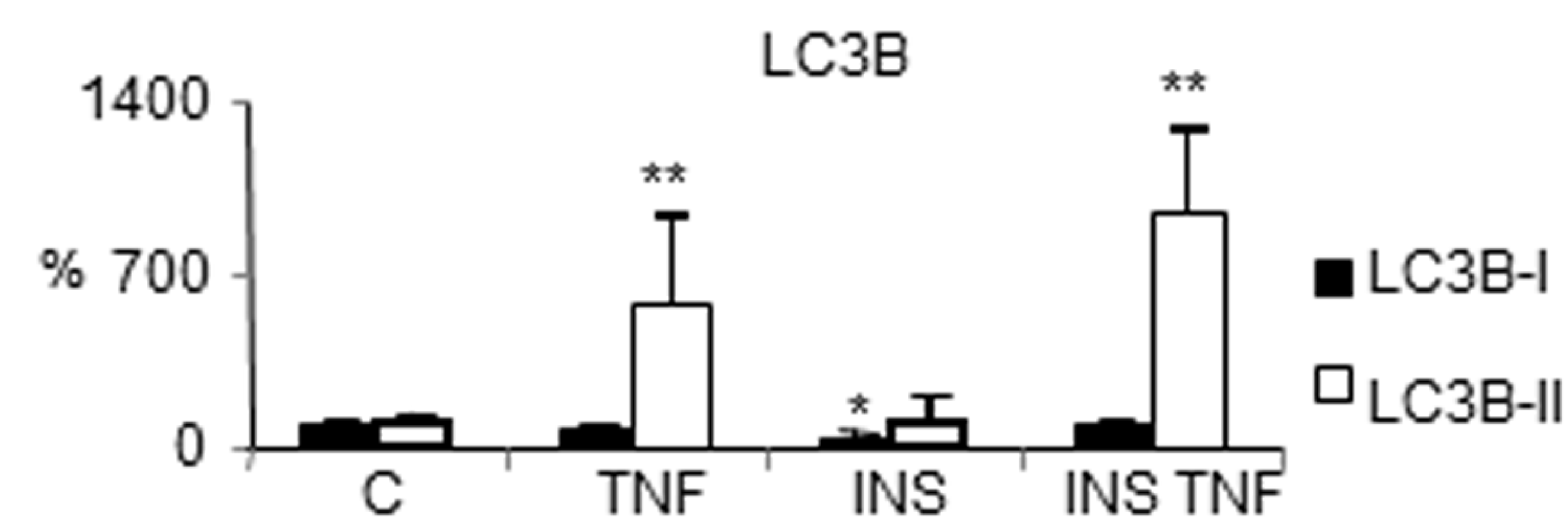

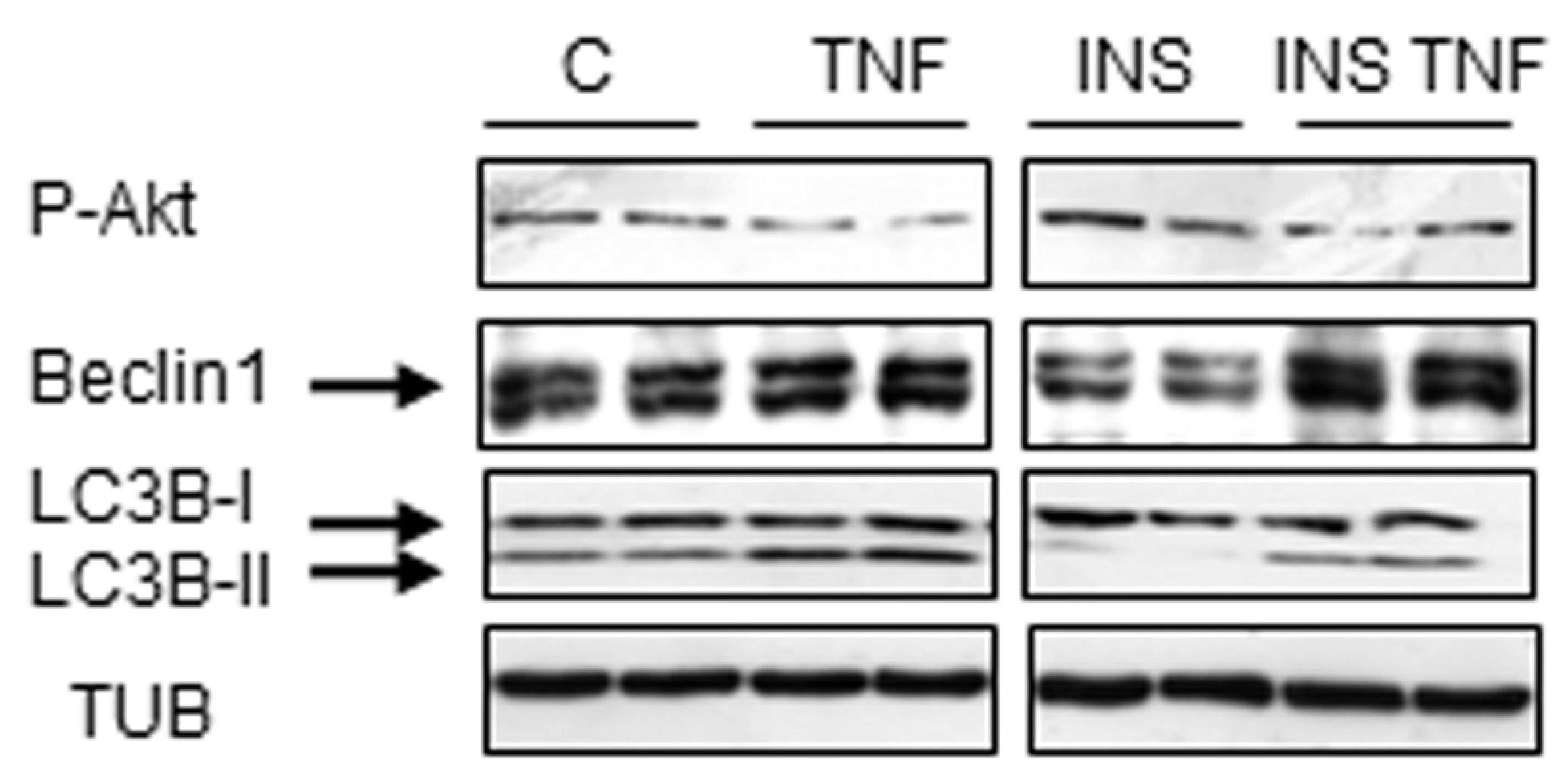

B
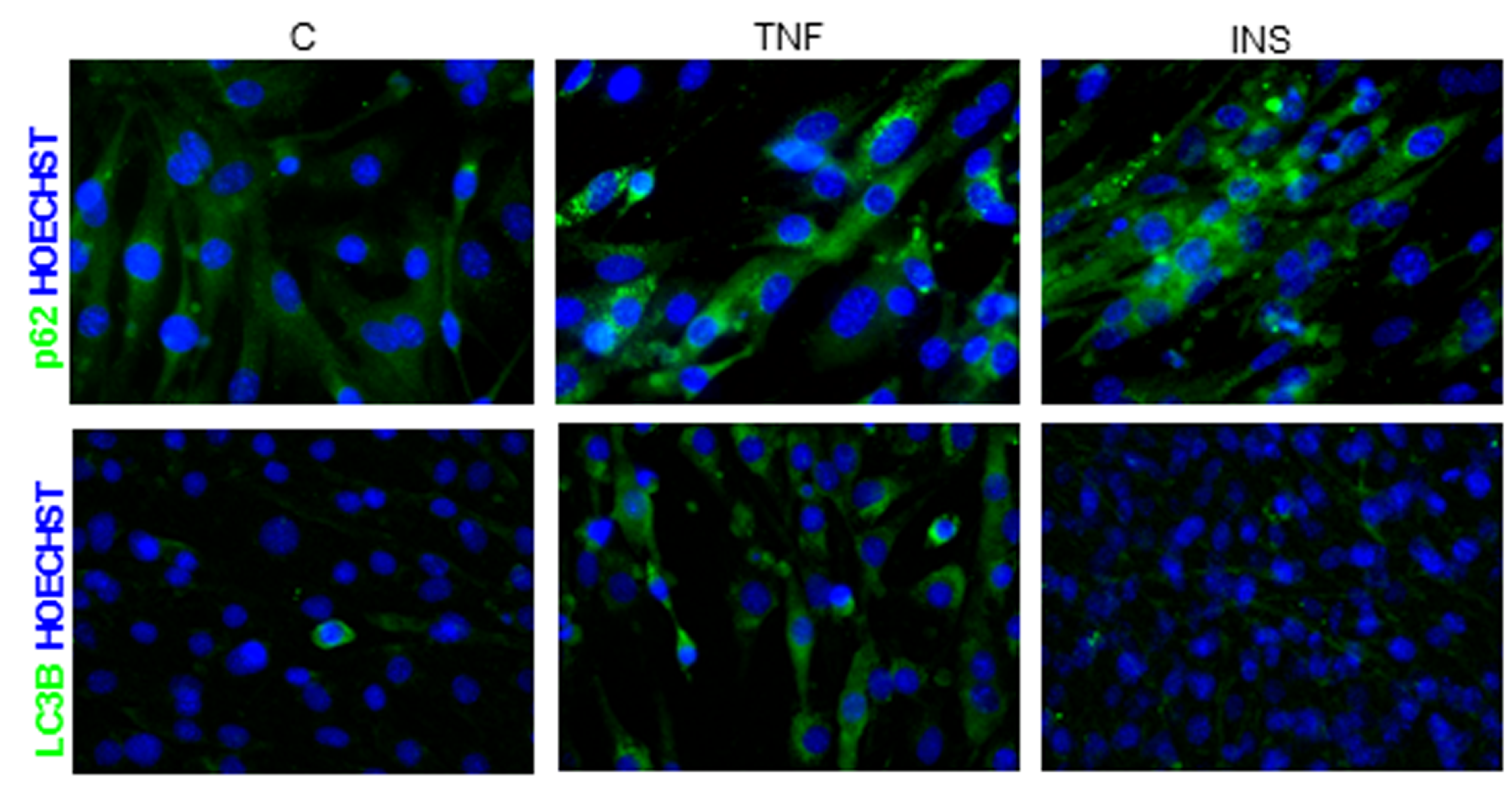

P-Akt (S473)

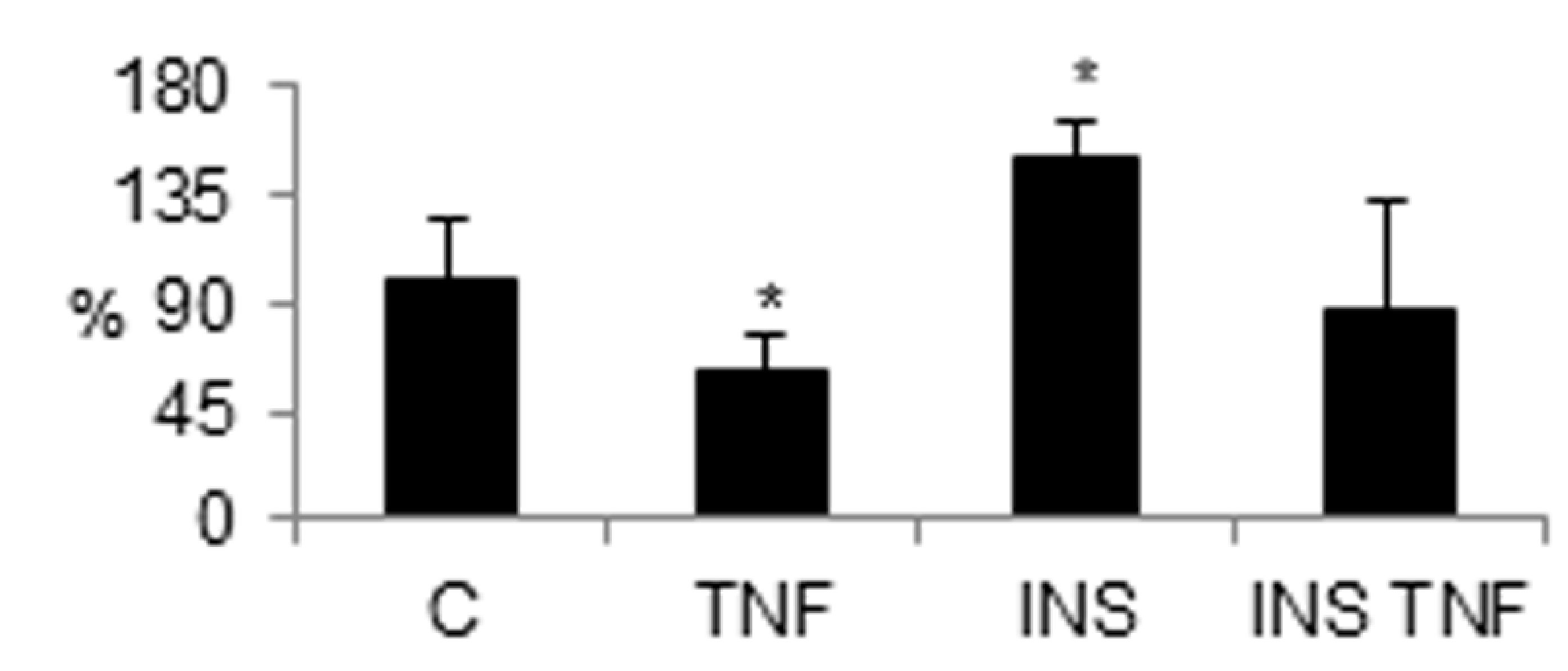

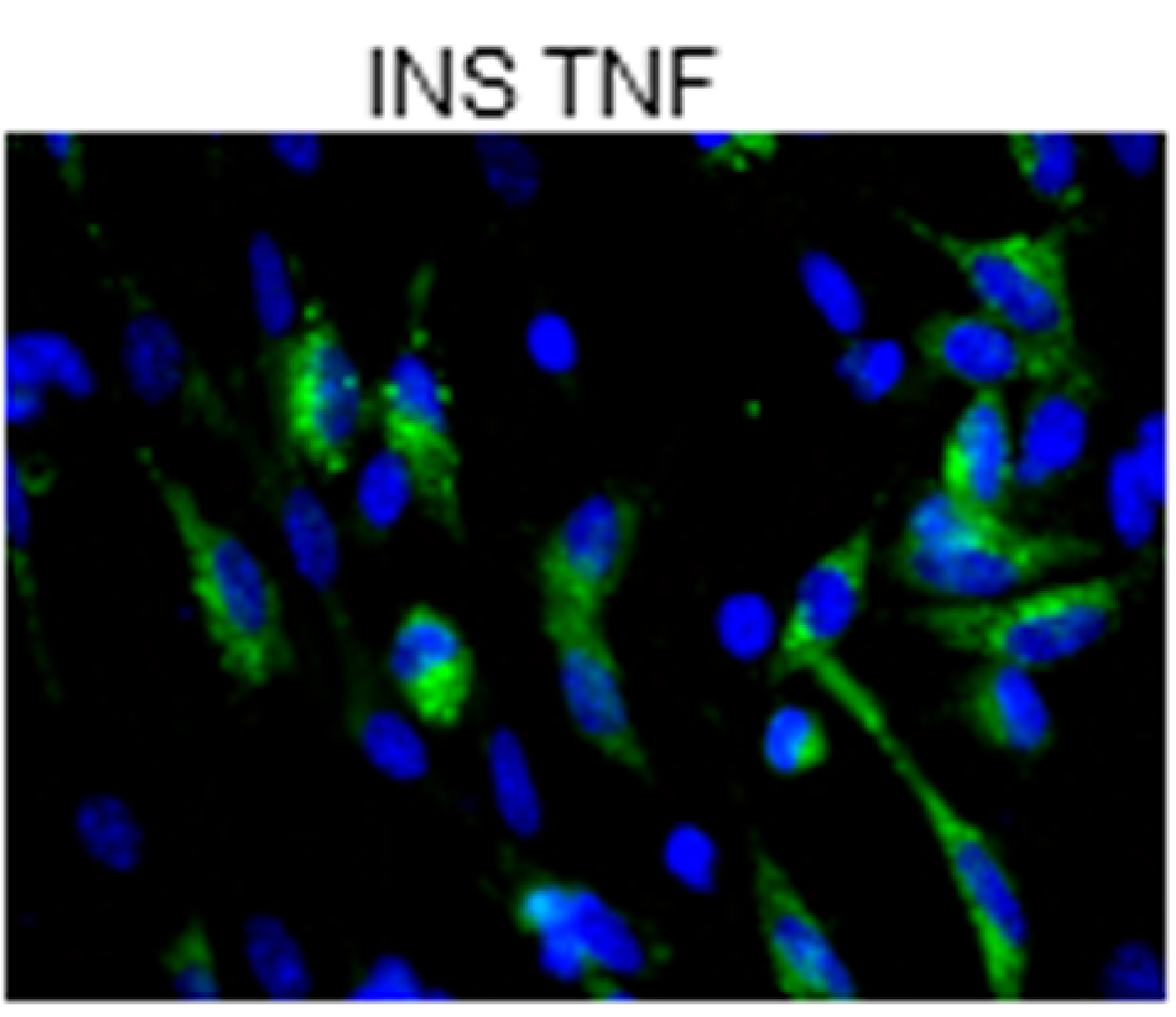

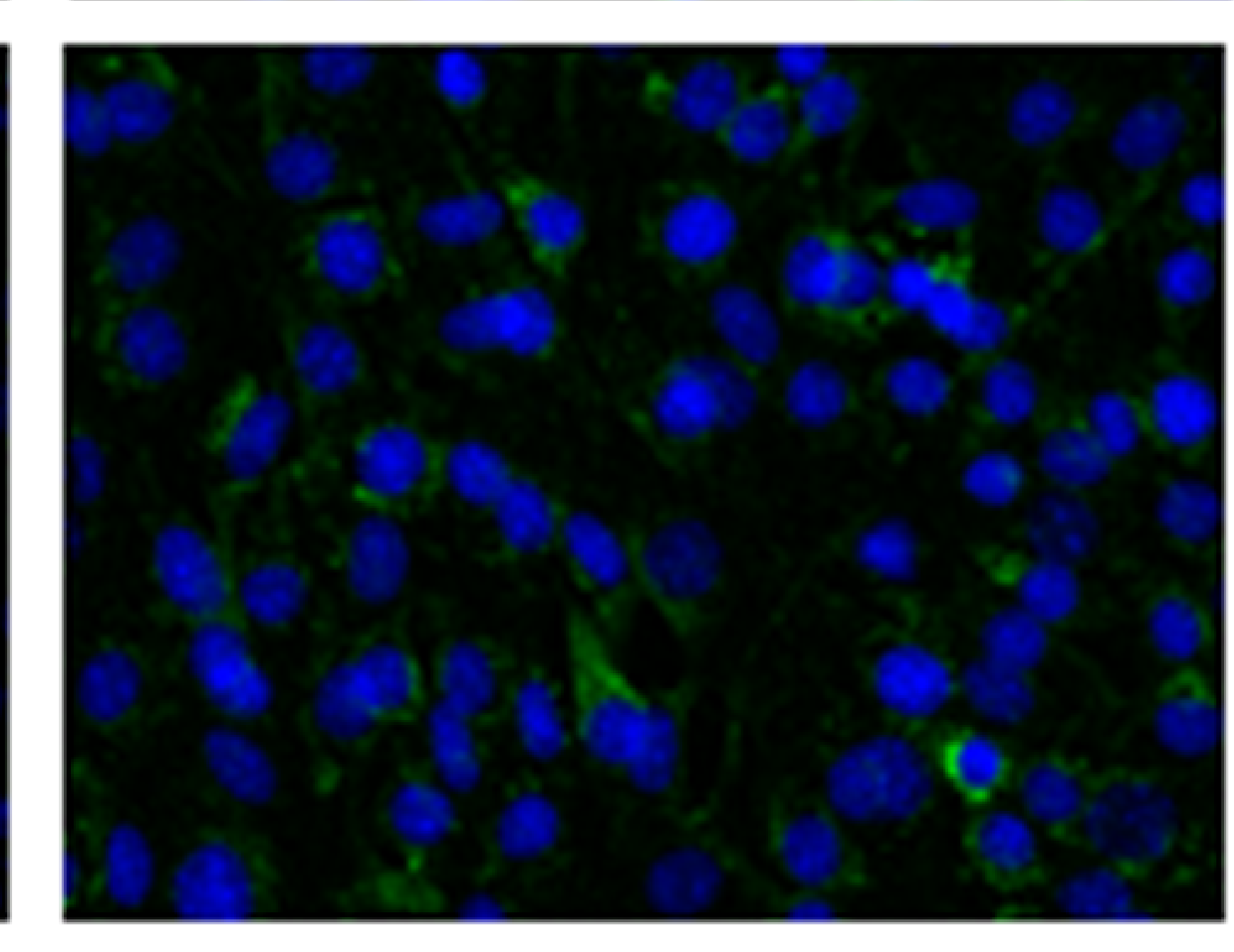


A

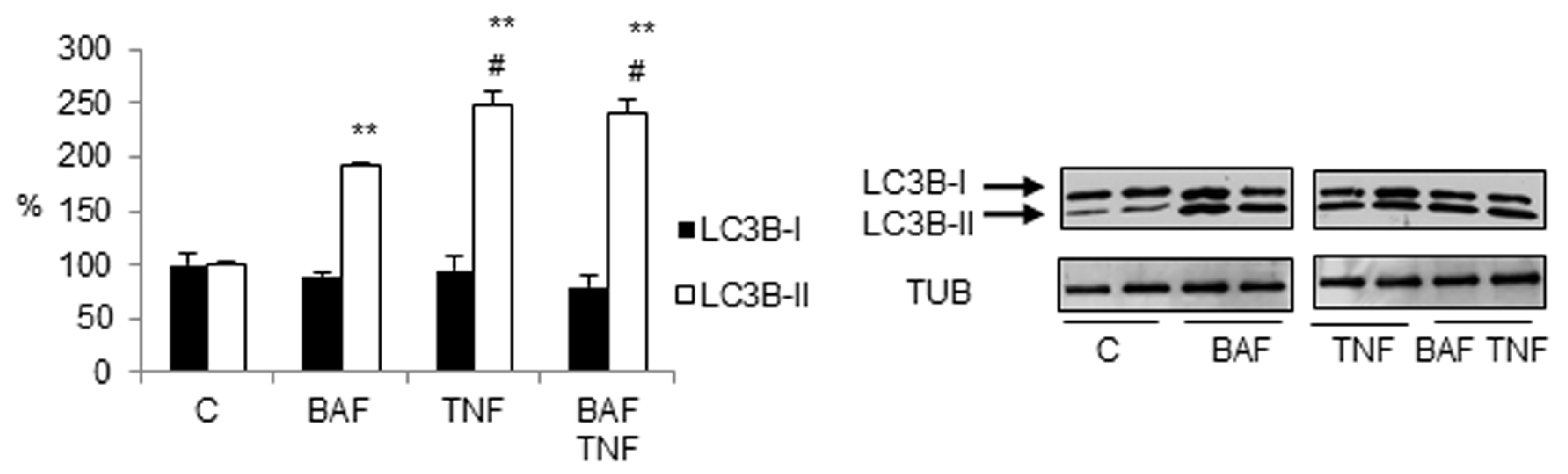

B

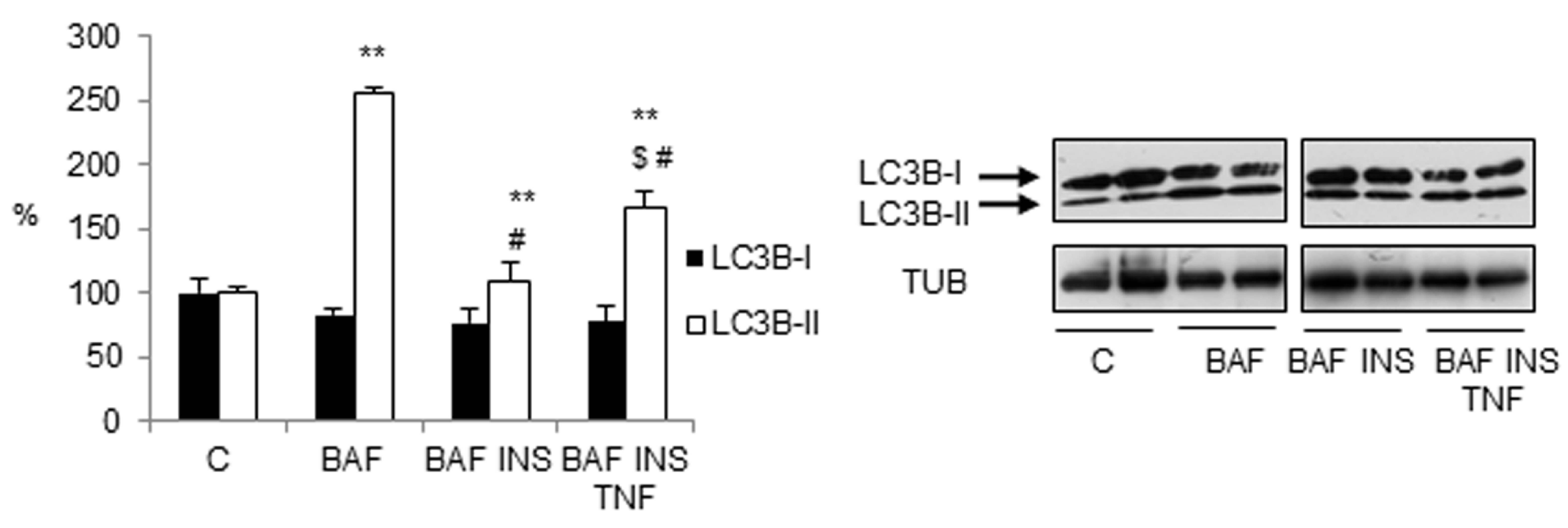

